\title{
Recurrent camouflaged invasions and dispersal of an Asian freshwater gastropod in tropical Africa
}

Bert Van Bocxlaer ${ }^{1,2,3,4^{*}}$, Catharina Clewing ${ }^{1}$, Jean-Papy Mongindo Etimosundja ${ }^{4,5}$, Alidor Kankonda ${ }^{5}$, Oscar Wembo Ndeo, ${ }^{5,6}$ and Christian Albrecht ${ }^{1}$

\begin{abstract}
Background: Non-indigenous taxa currently represent a large fraction of the species and biomass of freshwater ecosystems. The accumulation of invasive taxa in combination with other stressors in these ecosystems may alter the habitats to which native taxa are adapted, which could elicit evolutionary changes in native populations and their ecological interactions. Assessing ecological and evolutionary consequences of invasions simultaneously may therefore be the most effective approach to study taxa with complex invasion histories. Here we apply such an integrated approach to the cerithioid gastropod Melanoides tuberculata, a model system in invasion biology.

Results: Molecular phylogenetics and ancestral range reconstructions allowed us to identify several independent Asian invasions in Lakes Malawi and Tanganyika, the Congo River, Nigeria and Cameroon. Some invasive M. tuberculata populations display much variation in shell morphology, and overlap in morphospace with $M$. tuberculata populations native to Africa. Experiments confirmed great ecophenotyic plasticity in some invasive populations, which, in combination with the overlap in disparity with native populations, masks invaders and their dispersal through Africa. Finally, the results of geographic modeling indicate that cryptic M. tuberculata invasions occurred primarily in densely populated areas.

Conclusions: We reveal the continental nature of invasions of Asian M. tuberculata to Africa. Several of the affected ecosystems have high endemicity in Cerithioidea: Lake Tanganyika has an unparalleled diversity in freshwater cerithioids (>10 endemic genera) and the Congo Basin and Lake Malawi are home to the two largest endemic species clusters of Melanoides in Africa ( $\sim 12$ and $\sim 8$ species, respectively). Cerithioids perform ecologically important functions in the benthic ecosystems of African freshwaters, but invaders and ecosystem change pose risks to their native diversity. We draw suggestions for more effective conservation strategies from our integrated approach.
\end{abstract}

Keywords: Phylogeny, Morphology, Ancient Lakes Malawi and Tanganyika, Congo River, Melanoides tuberculata, Biogeography, Ecosystem change, Anthropogenic stressor, Feedback mechanisms

\section{Background}

Introductions of non-indigenous species are among the least reversible of human impacts on the world's ecosystems [1]. They decrease global biodiversity via the extirpation of native faunas and biotic homogenization, and

\footnotetext{
* Correspondence: bert.vanbocxlaer@ugent.be

'Department of Animal Ecology and Systematics, Justus Liebig University Giessen, Heinrich-Buff-Ring 26-32 (IFZ), D-35392 Giessen, Germany

${ }^{2}$ Departments of Paleobiology and Invertebrate Zoology, National Museum of Natural History, Smithsonian Institution, 10th and Constitution NW,

Washington, DC 20560, USA

Full list of author information is available at the end of the article
}

regularly cause considerable economic loss [2-5]. The world's freshwater ecosystems are heavily affected by biological invasions, and non-indigenous taxa constitute a large fraction of the species, individuals, and biomass in such ecosystems. In North America and Europe at least 1,176 freshwater invaders have been recorded $[1,6]$, but for tropical Africa knowledge is more limited. Nevertheless, African examples exist in a wide variety of taxa, including plants, invertebrates and vertebrates, and some of these cases illustrate the deep and far-reaching ecological impacts of invaders across various ecosystem

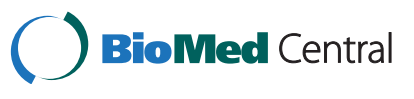

(c) 2015 Van Bocxlaer et al.; licensee BioMed Central. This is an Open Access article distributed under the terms of the Creative Commons Attribution License (http://creativecommons.org/licenses/by/4.0), which permits unrestricted use, distribution, and reproduction in any medium, provided the original work is properly credited. The Creative Commons Public Domain Dedication waiver (http://creativecommons.org/publicdomain/zero/1.0/) applies to the data made available in this article, unless otherwise stated. 
levels. Perhaps the most renowned and ecologically devastating example from Afrotropical freshwaters comes from Lake Victoria, where the Nile Perch (Lates niloticus) was introduced [7]. This invasive piscivore drove many of the 500+ endemic cichlid fishes to extinction [8], and, aided by other stressors, including eutrophication and blooms of the invasive water hyacinth Eichhornia, caused rapid and wholesale ecosystem change in the lake [9]. Although the introduction of the Nile Perch can be considered economically lucrative, it increased economic stratification and because the fish is locally unaffordable [10] it perhaps did not increase availability of animal protein to the local population.

The case of Lake Victoria substantiates (1) that freshwater biodiversity regularly faces the effects of several anthropogenic stressors at once $[11,12]$, (2) that the effects of invasions can be particularly devastating in isolated, eco-insular systems such as the African Great Lakes $[13,14]$, and (3) that biological invasions may drastically alter ecological and evolutionary patterns in ecosystems and their native biota $[15,16]$. Hence, the case underscores the relevance of approaches that investigate invasion dynamics and effects simultaneously at various biological levels (e.g. invasive populations, community effects, emerging continental patterns), especially for taxa with complex invasion histories.

Here we study African populations of the cerithioid gastropod Melanoides tuberculata (Müller, 1774), a model system in invasive biology [17]. The species is polyploidy and has a mixed reproductive system with parthenogenetic and sexual reproduction [18]. Sexual reproduction is rare, resulting in the persistence of entire genotypes for many generations $[17,18]$. Because of the predominant parthenogenetic reproduction, local populations of a genetic clone usually display limited morphological variation [18]. As a result, previous authors [18-22] have characterized clonal populations as morphs, and have assigned three-letter codes to these morphs.

Indigenous strains of $M$. tuberculata occur on the African continent but around the 1980s, an Asian lineage of M. tuberculata (LMI morphs) invaded Lake Malawi [21]. This invasion remained long unnoticed, although the invasive morphs have a characteristic morphology, because morphological variation within and between indigenous $M$. tuberculata morphs is poorly understood, so that native lineages camouflage the invader's presence. Consequently, variation in other indigenous African populations of $M$. tuberculata may likewise obscure the presence of invaders, which hampers our understanding of colonization history and therewith appropriate monitoring and conservation strategies. Moreover, the invader became fully established in Lake Malawi [23], and recent changes in ecological interactions have resulted in marked responses in the benthic community [24]. The camouflaged invasion and its ecological and evolutionary consequences in Lake Malawi urge further investigations of the invasion history of $M$. tuberculata on the African continent. Because $M$. tuberculata has a notorious invasion history in the Neotropics [17,20], and because knowledge on its African invasions is comparatively limited, we investigate the species with an integrated approach.

First, we produce a backbone phylogeny that allows assessing phylogeographic patterns, evolutionary history and therewith molecular screening of new Melanoides collections spanning the East African Rift and surroundings for potential invaders. Morphological studies of wildcollected and lab-bred specimens were conducted to obtain insights into the variability of shell morphology in M. tuberculata, and combined with the phylogeny into genotype-phenotype relationships. Integration of morphological and molecular data is particularly important because some gastropods have been misperceived as invasive [25], and because phenotypic plasticity and genetic variation influence dispersal capabilities and, hence, 'invasiveness' $[15,26]$. Moreover, a better understanding of shell morphology would facilitate morphological identifications of invasive strains in the field. Using geographical modeling we also investigate how humans and anthropogenic stressors affect the invasion history of $M$. tuberculata in Africa. Finally, we discuss the implications of our findings to conservation strategies for African freshwater habitats.

\section{Methods}

\section{Sampling and experimental procedures}

We collected material from the Congo River, its tributaries and the Lake Edward region of the Democratic Republic of Congo (DRC), from Lake Tanganyika in Burundi, Lake Malawi and the Shire River in Malawi, Lake Kivu in Rwanda, and Lakes Kyoga and Edward, and the Victorian Nile River in Uganda (all between 2006 and 2012), and supplemented this material with previously published samples (Table 1; Figure 1). Material collected for phylogenetic studies was preserved in $80 \% \mathrm{EtOH}$. Specimens of one Melanoides population ( $n=40$; 09-032; CD05-CD06) from Kisangani (DRC) were maintained and bred in laboratory tanks after which the shell morphology of wildcaught parents, lab-bred $F_{1}$ offspring, and other populations of $M$. tuberculata were compared. For the experiment we used a $100 \mathrm{l}$ tank that had been set up before for common garden experiments with endemic gastropods from Lake Malawi (seeded with Malawi sand and water; see [27]). Water conditions reflected those of Lake Malawi ( $\mathrm{pH} \sim 8.0 ; \mathrm{T}=\sim 26^{\circ} \mathrm{C}$ ), but with a higher amount of dissolved oxygen $(\sim 6.0 \mathrm{~mL} / \mathrm{L}$ instead of $3.5-4.0 \mathrm{~mL} / \mathrm{L}$ ), and a higher electrical conductivity (increased bicarbonate hardness; $\sim 1,800 \mu \mathrm{S} / \mathrm{cm}$ instead of $\sim 260 \mu \mathrm{S} / \mathrm{cm}$ in the lake) to prevent shell corrosion. 
Table 1 Identification, collecting information, and NCBI GenBank accession numbers for specimens included in molecular analyses

\begin{tabular}{|c|c|c|c|c|c|c|c|c|}
\hline \multirow[b]{2}{*}{ Specimen code } & \multirow[b]{2}{*}{ Taxon } & \multirow[b]{2}{*}{ Country } & \multirow[b]{2}{*}{ Locality } & \multirow[b]{2}{*}{ Year } & \multirow[b]{2}{*}{$\begin{array}{l}\text { Prep } \\
\text { No. }\end{array}$} & \multicolumn{2}{|c|}{ GenBank numbers } & \multirow[b]{2}{*}{ Morph } \\
\hline & & & & & & $\mathrm{COI}$ & $16 \mathrm{~S}$ & \\
\hline $\mathrm{Bl} 01 / 1$ & M. tuberculata & Burundi & Lake Tanganyika & 2012 & 19052 & KP774674 & KP774633 & BIT \\
\hline $\mathrm{B} \mid 01 / 2$ & M. tuberculata & Burundi & Lake Tanganyika & 2012 & 21072 & KP774675 & KP774634 & BIT \\
\hline $\mathrm{BI} 01 / 3$ & M. tuberculata & Burundi & Lake Tanganyika & 2012 & 21073 & KP774676 & KP774635 & BIT \\
\hline $\mathrm{BI} 01 / 4$ & M. tuberculata & Burundi & Lake Tanganyika & 2012 & 21074 & KP774677 & KP774636 & BIT \\
\hline $\mathrm{BI} 01 / 5$ & M. tuberculata & Burundi & Lake Tanganyika & 2012 & 21096 & KP774678 & KP774637 & BIT \\
\hline $\mathrm{BI} 01 / 6$ & M. tuberculata & Burundi & Lake Tanganyika & 2012 & 21097 & KP774679 & KP774638 & BIT \\
\hline $\mathrm{B} 101 / 7$ & M. tuberculata & Burundi & Lake Tanganyika & 2012 & 21098 & KP774680 & KP774639 & BIT \\
\hline CD15/1* & M. anomala & DR Congo & Mwati River, Shaba Province (= Katanga) & & & AY958726 & & n.a. \\
\hline CD15/2* & M. anomala & DR Congo & Kiseru River, Shaba Province (=Katanga) & & & AY958727 & & n.a. \\
\hline CD01/1 & M. tuberculata & DR Congo & Kisangani, Makiso (09-031) & 2009 & 16491 & KP774681 & KP774640 & CDI \\
\hline CD02/1 & M. cf. liebrechtsi & DR Congo & Congo-Itimbiri (Engengele; 09-023) & 2009 & 19042 & KP774682 & KP774641 & n.a. \\
\hline CD02/2 & M. cf. liebrechtsi & DR Congo & Congo-Itimbiri (Engengele; 09-023) & 2009 & 19043 & KP774683 & & n.a. \\
\hline CD02/3 & M. cf. nsendweensis & DR Congo & Congo-Itimbiri (Engengele; 09-023) & 2009 & 19044 & KP774684 & KP774642 & n.a. \\
\hline CD03/1 & M. cf. liebrechtsi & DR Congo & Aruwimi River (Basoko; 09-027A) & 2009 & 19048 & KP774685 & & n.a. \\
\hline CD04/1 & M. cf. liebrechtsi & DR Congo & Aruwimi River (Basoko; 09-027B) & 2009 & 19046 & KP774686 & KP774643 & n.a. \\
\hline CD05/1 & M. tuberculata & DR Congo & Kisangani, Makiso (09-032A) & 2009 & 16493 & KP774687 & & CDI \\
\hline CD06/1 & M. tuberculata & DR Congo & Kisangani, Makiso (09-032B) & 2009 & 16495 & KP774688 & KP774644 & CDI \\
\hline CD07/1 & M. tuberculata & DR Congo & Kisangani, Kitenge (09-033) & 2009 & 16499 & KP774689 & KP774645 & CDI \\
\hline CD08/1 & M. cf. liebrechtsi & DR Congo & Aruwimi River (Yakoyo; KM10-011) & 2010 & 19040 & KP774690 & KP774646 & n.a. \\
\hline CD09/1 & M. tuberculata & DR Congo & Ngenengene River & 2012 & 18588 & KP774691 & KP774647 & CDI \\
\hline CD09/2 & M. tuberculata & DR Congo & Ngenengene River & 2012 & 18589 & KP774692 & KP774648 & CDI \\
\hline CD10/1 & M. tuberculata & DR Congo & Avokoko River & 2012 & 18592 & KP774693 & KP774649 & CDI \\
\hline CD10/2 & M. tuberculata & DR Congo & Avokoko River & 2012 & 18593 & KP774694 & KP774650 & CDI \\
\hline CD10/3 & M. tuberculata & DR Congo & Avokoko River & 2012 & 18594 & KP774695 & & CDI \\
\hline CD10/4 & M. tuberculata & DR Congo & Avokoko River & 2012 & 18595 & KP774696 & KP774651 & CDI \\
\hline CD11/1 & M. tuberculata & DR Congo & Kpalala River & 2012 & 18596 & KP774697 & KP774652 & CDI \\
\hline CD11/2 & M. tuberculata & DR Congo & Kpalala River & 2012 & 18597 & KP774698 & KP774653 & CDI \\
\hline CD11/3 & M. tuberculata & DR Congo & Kpalala River & 2012 & 18598 & KP774699 & KP774654 & CDI \\
\hline CD11/4 & M. tuberculata & DR Congo & Kpalala River & 2012 & 18599 & KP774700 & KP774655 & CDI \\
\hline CD12/1 & M. tuberculata & DR Congo & Lake Edward & 2010 & 18606 & KP774701 & KP774656 & CLE \\
\hline CD13/1 & M. tuberculata & DR Congo & Taliha River & 2010 & 18608 & KP774702 & KP774657 & CTA \\
\hline CD14/1 & M. tuberculata & DR Congo & Semliki River & 2010 & 18610 & KP774703 & & $\mathrm{CSM}_{1}$ \\
\hline CD14/2 & M. tuberculata & DR Congo & Semliki River & 2010 & 18611 & KP774704 & KP774658 & $\mathrm{CSM}_{2}$ \\
\hline $\mathrm{PF} 01 / 1^{*}$ & M. tuberculata & French Polynesia & & 1998 & & AF236072 & & FPO \\
\hline $\mathrm{PF} 02 / 1^{*}$ & M. tuberculata & French Polynesia & & 1998 & & AF236071 & & FPO \\
\hline IL01/1* & M. tuberculata & Israel & Ilan & 1993 & & AY575994 & & ISR \\
\hline $\mathrm{KE} 01 / 1^{*}$ & M. tuberculata & Kenya & Lake Victoria & & & AY791913 & AY791931 & KLV \\
\hline MW01/1* & M. tuberculata & Malawi & Kambiri Point, Lake Malawi & $99-02$ & & AY575992 & & $\mathrm{LMI}_{1}$ \\
\hline $\mathrm{MW} 02 / 1^{*}$ & M. tuberculata & Malawi & Makakola, Lake Malawi & $99-02$ & & AY575980 & & $\mathrm{LMI}_{4}$ \\
\hline $\mathrm{MWO3} / 1^{*}$ & M. tuberculata & Malawi & Cape Maclear, Lake Malawi & $99-02$ & & AY575985 & & $\mathrm{LMI}_{2}$ \\
\hline MW03/13 & M. tuberculata & Malawi & Cape Maclear, Lake Malawi & 2006 & 21086 & KP774705 & KP774659 & LMI \\
\hline MW03/14 & M. tuberculata & Malawi & Cape Maclear, Lake Malawi & 2006 & 21087 & KP774706 & & LMI \\
\hline
\end{tabular}


Table 1 Identification, collecting information, and NCBI GenBank accession numbers for specimens included in molecular analyses (Continued)

\begin{tabular}{|c|c|c|c|c|c|c|c|c|}
\hline MW03/15 & M. tuberculata & Malawi & Cape Maclear, Lake Malawi & 2006 & 21090 & KP774707 & KP774660 & LMN \\
\hline MW04/1* & M. tuberculata & Malawi & Mkungula, Lake Malombe & $99-02$ & & AY575990 & & $\mathrm{LMN}_{3}$ \\
\hline MW05/1* & M. tuberculata & Malawi & Nkhata Bay, Lake Malawi & $99-02$ & & AY575993 & & $\mathrm{LMN}_{1}$ \\
\hline MW05/2* & M. tuberculata & Malawi & Nkhata Bay, Lake Malawi & $99-02$ & & AY575998 & & $\mathrm{LMN}_{1}$ \\
\hline MW06/1* & M. tuberculata & Malawi & Southern part of Lake Malawi & 2002 & & AY791912 & & $\mathrm{MAC}_{1}$ \\
\hline MW10/1 & M. tuberculata & Malawi & Monkey Bay, Lake Malawi & 2006 & 21066 & KP774708 & KP774661 & LMI \\
\hline MW10/2 & M. tuberculata & Malawi & Monkey Bay, Lake Malawi & 2006 & 21080 & KP774709 & KP774662 & LMI \\
\hline MW10/3 & M. tuberculata & Malawi & Monkey Bay, Lake Malawi & 2006 & 21081 & & KP774663 & LMN \\
\hline MW11/1 & M. tuberculata & Malawi & Chipoka, Lake Malawi & 2006 & 21068 & KP774710 & KP774664 & LMI \\
\hline MW11/2 & M. tuberculata & Malawi & Chipoka, Lake Malawi & 2006 & 21069 & KP774711 & KP774665 & LMI \\
\hline MW12/1 & M. tuberculata & Malawi & Zalewa, Shire River & 2006 & 21070 & KP774712 & KP774666 & LMI \\
\hline MW13/1 & M. tuberculata & Malawi & Chilumba, Lake Malawi & 2006 & 21082 & & KP774667 & LMI \\
\hline MW13/2 & M. tuberculata & Malawi & Chilumba, Lake Malawi & 2006 & 21084 & KP774713 & & LMN \\
\hline MW14/1 & M. tuberculata & Malawi & Karonga, Lake Malawi & 2006 & 21093 & & KP774668 & LMI \\
\hline MW03/2* & M. polymorpha & Malawi & Cape Maclear, Lake Malawi & & & AY958744 & & $M P_{D}$ \\
\hline MW03/3* & M. polymorpha & Malawi & Cape Maclear, Lake Malawi & & & AY958729 & & $\mathrm{MP}_{\mathrm{C}}$ \\
\hline MW03/4* & M. polymorpha & Malawi & Cape Maclear, Lake Malawi & & & AY958731 & & $\mathrm{MP}_{\mathrm{E}}$ \\
\hline MW03/5* & M. polymorpha & Malawi & Cape Maclear, Lake Malawi & & & AY958747 & & $M P_{D}$ \\
\hline MW03/6* & M. polymorpha & Malawi & Cape Maclear, Lake Malawi & & & AY958730 & & $\mathrm{MP}_{\mathrm{B}}$ \\
\hline $\mathrm{MW03} / 7^{*}$ & M. polymorpha & Malawi & Cape Maclear, Lake Malawi & & & AY958728 & & $\mathrm{MP}_{\mathrm{c}}$ \\
\hline MW03/8* & M. polymorpha & Malawi & Cape Maclear, Lake Malawi & & & AY958742 & & $\mathrm{MP}_{\mathrm{A}}$ \\
\hline MW03/9* & M. polymorpha & Malawi & Cape Maclear, Lake Malawi & & & AY958746 & & $M P_{D}$ \\
\hline $\mathrm{MW03} / 10^{*}$ & M. polymorpha & Malawi & Cape Maclear, Lake Malawi & & & AY958743 & & $\mathrm{MP}_{\mathrm{A}}$ \\
\hline $\mathrm{MWO} / 11^{*}$ & M. polymorpha & Malawi & Cape Maclear, Lake Malawi & & & AY958745 & & $M P_{D}$ \\
\hline $\mathrm{MW} 03 / 12^{*}$ & M. polymorpha & Malawi & Cape Maclear, Lake Malawi & & & AY958732 & & $\mathrm{MP}_{\mathrm{E}}$ \\
\hline MW05/3* & M. polymorpha & Malawi & Nkhata Bay, Lake Malawi & & & AY958756 & & $\mathrm{MP}_{1}$ \\
\hline MW05/4* & M. polymorpha & Malawi & Nkhata Bay, Lake Malawi & & & AY958733 & & $\mathrm{MP}_{\mathrm{K}}$ \\
\hline MW05/5* & M. polymorpha & Malawi & Nkhata Bay, Lake Malawi & & & AY958736 & & $M P_{L}$ \\
\hline MW05/6* & M. polymorpha & Malawi & Nkhata Bay, Lake Malawi & & & AY958752 & & MP, \\
\hline MW05/7* & M. polymorpha & Malawi & Nkhata Bay, Lake Malawi & & & AY958740 & & $\mathrm{MP}_{\mathrm{I}}$ \\
\hline MW05/8* & M. polymorpha & Malawi & Nkhata Bay, Lake Malawi & & & AY958738 & & $M P_{1}$ \\
\hline MW05/9* & M. polymorpha & Malawi & Nkhata Bay, Lake Malawi & & & AY958734 & & $\mathrm{MP}_{\mathrm{G}}$ \\
\hline MW05/10* & M. polymorpha & Malawi & Nkhata Bay, Lake Malawi & & & AY958741 & & $\mathrm{MP}_{\mathrm{J}}$ \\
\hline MW05/11* & M. polymorpha & Malawi & Nkhata Bay, Lake Malawi & & & AY958739 & & $\mathrm{MP}_{1}$ \\
\hline MW05/12* & M. polymorpha & Malawi & Nkhata Bay, Lake Malawi & & & AY958737 & & $\mathrm{MP}_{\mathrm{H}}$ \\
\hline MW05/13* & M. polymorpha & Malawi & Nkhata Bay, Lake Malawi & & & AY958735 & & $M P_{L}$ \\
\hline $\mathrm{PH} 01 / 1^{*}$ & M. tuberculata & Philippines & Luzon; mountain stream N. of Iba & 2000 & & AY456564 & & $\mathrm{PHI}_{1}$ \\
\hline RW01/1 & M. tuberculata & Rwanda & Lake Kivu & 2010 & 19037 & KP774714 & KP774669 & RLK \\
\hline RW01/2 & M. tuberculata & Rwanda & Lake Kivu & 2010 & 19039 & KP774715 & & RLK \\
\hline $\mathrm{SG} 01 / 1^{*}$ & M. tuberculata & Singapore & Lower Selatar Reservoir & 2003 & & AY575978 & & LSR \\
\hline $\mathrm{SG} 02 / 1^{*}$ & M. tuberculata & Singapore & Napier Road & 2003 & & AY575972 & & NAP \\
\hline $\mathrm{SG} 03 / 1^{*}$ & M. tuberculata & Singapore & Pandan Reservoir & 2003 & & AY575974 & & PAN \\
\hline $\mathrm{SG} 03 / 2^{*}$ & M. tuberculata & Singapore & Pandan Reservoir & 2003 & & AY575975 & & PAN \\
\hline $\mathrm{SG} 04 / 1^{*}$ & M. tuberculata & Singapore & Upper Selatar Reservoir & 2003 & & AY575977 & & USR \\
\hline
\end{tabular}


Table 1 Identification, collecting information, and NCBI GenBank accession numbers for specimens included in molecular analyses (Continued)

\begin{tabular}{|c|c|c|c|c|c|c|c|c|}
\hline $\mathrm{SG} 04 / 2^{*}$ & M. tuberculata & Singapore & Upper Selatar Reservoir & 2003 & & AY575979 & & USR \\
\hline $\mathrm{SG} 05 / 1^{*}$ & Thiara scabra & Singapore & Lower Selatar Reservoir & 2003 & & AY958758 & & n.a. \\
\hline $\mathrm{SG} 05 / 2^{*}$ & Tarebia granifera & Singapore & Lower Selatar Reservoir & 2003 & & AY958760 & & n.a. \\
\hline SG05/3* & Tarebia granifera & Singapore & Chinese Garden & 2003 & & AY958761 & & n.a. \\
\hline $\mathrm{SG} 05 / 4^{*}$ & Tarebia granifera & Singapore & Lower Selatar Reservoir & 2003 & & AY958762 & & n.a. \\
\hline $\mathrm{SG} 05 / 5^{*}$ & Tarebia granifera & Singapore & Napier Road & 2003 & & AY958763 & & n.a. \\
\hline $\mathrm{SG} 05 / 6^{*}$ & Tarebia granifera & USA & Miami, Florida & 2003 & & AY958764 & & n.a. \\
\hline SO01/1* & M. tuberculata & Somalia & Eil Spring & 1992 & & AY575973 & & SOM \\
\hline TZO1/1* & M. tuberculata & Tanzania & Mwanza Gulf, Lake Victoria & 2002 & & AY575996 & & VIC \\
\hline TZO1/2* & M. tuberculata & Tanzania & Mwanza Gulf, Lake Victoria & 2002 & & AY575995 & & VIC \\
\hline TZO2/1* & M. tuberculata & Tanzania & Itungi, Lake Malawi & 2002 & & AY791909 & AY791910 & TAI \\
\hline TZO3/1* & M. admirabilis & Tanzania & Malagarasi River & & & AY958725 & & n.a. \\
\hline UG01/1 & M. tuberculata & Uganda & Jinja, Victoria Nile & 2010 & 18600 & KP774716 & KP774670 & UNI \\
\hline UG02/1 & M. tuberculata & Uganda & Lake Kyoga & 2010 & 18602 & KP774717 & KP774671 & ULK \\
\hline UG03/1 & M. tuberculata & Uganda & Lake Edward & 2010 & 18604 & KP774718 & KP774672 & ULE \\
\hline ZM01/1* & M. imitatrix & Zambia & Isokwe Island, Lake Mweru & & & DQ995480 & & n.a. \\
\hline $\mathrm{ZMO} / 1^{*}$ & M. imitatrix & Zambia & Isokwe Island, Lake Mweru & & & DQ995479 & & n.a. \\
\hline $\mathrm{ZMO3/1^{* }}$ & M. mweruensis & Zambia & Kilwa Island, Lake Mweru & & & DQ995481 & & n.a. \\
\hline TZO6/1* & M. admirabilis & Tanzania & Malagarasi River & 2000 & & AY456561 & & n.a. \\
\hline MW05/14* & M. woodwardi & Malawi & Nkhata Bay, Lake Malawi & 2002 & & & AY791903 & WOO \\
\hline $\mathrm{MW} 07 / 1^{*}$ & M. turritispira & Malawi & Nkhota Kota, Lake Malawi & 2002 & & & AY791908 & TUR \\
\hline $\mathrm{CA01/1*}$ & M. tuberculata & Cameroon & Eseka & & & & AY791914 & CAE \\
\hline MW08/1* & M. tuberculata & Malawi & Chembe, Lake Malawi & 2002 & & & AY791915 & $\mathrm{MAC}_{1}$ \\
\hline TZO4/1* & M. truncatelliformis & Tanzania & Mwaya, Lake Malawi & 2002 & & & AY791917 & TRU \\
\hline TZO4/2* & M. simonsi & Tanzania & Mwaya, Lake Malawi & 2002 & & & AY791918 & TAM \\
\hline TZO5/1* & M. pupiformis & Tanzania & Kiwira, Lake Malawi & 2002 & & & AY791920 & PUB \\
\hline TZO4/3* & M. polymorpha & Tanzania & Mwaya, Lake Malawi & 2002 & & & AY791924 & POL \\
\hline $\mathrm{TZO5} / 2^{*}$ & M. nodicincta & Tanzania & Kiwira, Lake Malawi & 2002 & & & AY791927 & TAK \\
\hline TZO4/4* & M. magnifica & Tanzania & Mwaya, Lake Malawi & 2002 & & & AY791928 & MAG \\
\hline TZO5/3* & M. nyassana & Tanzania & Kiwira, Lake Malawi & 2002 & & & AY791933 & NYA \\
\hline CD15/1* & M. tuberculata & DR Congo & Kinshasa & 1994 & & & AY283067 & ZAK \\
\hline FW01/1* & M. amabilis & French West Indies & Martinique & 2000 & & & AY283068 & n.a. \\
\hline FW01/2* & M. tuberculata & French West Indies & Martinique & 1999 & & & AY283071 & PDC \\
\hline $\mathrm{ICO} / 1^{*}$ & M. tuberculata & Ivory Coast & Bouaké & 1995 & & & AY283072 & $\mathrm{BOU}$ \\
\hline OM01/1* & M. tuberculata & Oman & Afilayia & 2000 & & & AY283073 & OMW \\
\hline $\mathrm{MO} 01 / 1^{*}$ & M. tuberculata & Morocco & Figuig & 1993 & & & AY283074 & MOF \\
\hline FW01/3* & M. tuberculata & French West Indies & Martinique & 1999 & & & AY283075 & FAL \\
\hline $\mathrm{KEO} / 1^{*}$ & M. tuberculata & Kenya & Kisumu, Lake Victoria & 2000 & & & AY283076 & KIS \\
\hline SY01/1* & M. tuberculata & Seychelles & & 2000 & & & AY283077 & ND \\
\hline $\mathrm{CO} 01 / 1^{*}$ & M. tuberculata & Colombia & San Jeronimo & 1999 & & & AY283078 & $\mathrm{COL}$ \\
\hline US01/1* & M. tuberculata & USA & Florida & 2000 & & & AY283079 & $\mathrm{BCl}$ \\
\hline PE01/1* & M. tuberculata & Peru & Tumbes & 1994 & & & AY283080 & TUM \\
\hline $\mathrm{IN} 01 / 1^{*}$ & M. tuberculata & Indonesia & Lombok & 2000 & & & AY283081 & ND \\
\hline $\mathrm{PF} 03 / 1^{*}$ & M. tuberculata & French Polynesia & Moorea & 1999 & & & AY283083 & $\mathrm{MOO}$ \\
\hline
\end{tabular}


Table 1 Identification, collecting information, and NCBI GenBank accession numbers for specimens included in molecular analyses (Continued)

\begin{tabular}{|c|c|c|c|c|c|c|c|c|}
\hline VE01/1* & M. tuberculata & Venezuela & Choroni & 2001 & & & AY283084 & $\mathrm{CHO}$ \\
\hline US02/1* & M. tuberculata & USA & Florida & 2000 & & & AY010517 & USF \\
\hline AR01/1* & M. tuberculata & Argentina & Misiones & & & & EF523385 & ARG \\
\hline MW09/1* & M. tuberculata & Malawi & Lake Malawi & $99-00$ & & & AY456616 & LMN \\
\hline US03/1* & M. tuberculata & USA & & & & & AF101006 & USX \\
\hline $\mathrm{PH} 01 / 2^{*}$ & M. tuberculata & Philippines & Luzon; mountain stream N. of Iba & 2000 & & & AY456618 & $\mathrm{PHI}_{2}$ \\
\hline$T Z 06 / 2^{*}$ & M. admirabilis & Tanzania & Malagarasi River & 2000 & & & AY456615 & n.a. \\
\hline MU01/1 & Thiara scabra & Mauritius & Pamplemousses, Citron River & 2013 & 20294 & KP774719 & KP774673 & n.a. \\
\hline PF04/1* & Tarebia granifera & French Polynesia & Tahiti & 1998 & & & AY283069 & n.a. \\
\hline ZA01/1* & Lavigeria grandis & Zambia & Lake Tanganyika, Kumbula Island & 1999 & & AY456539 & & n.a. \\
\hline ZA01/1* & Lavigeria grandis & Zambia & Lake Tanganyika, Kasenga Point & 1999 & & & AY456594 & n.a. \\
\hline $\mathrm{SP} 01 / 1^{*}$ & Hydrobia glyca & Spain & San Vicente de la Barquera & & & AF467653 & & n.a. \\
\hline $\mathrm{SP} 01 / 2^{*}$ & Hydrobia glyca & Spain & San Fernando & & & & AF478397 & n.a. \\
\hline
\end{tabular}

When species determination was ambiguous (e.g. for juveniles), we added cf. to the species names. Shells were usually broken during DNA isolation; tissue and shells or fragments are stored at the Justus Liebig University, Giessen and indicated with DNA preparation numbers (UGSB collection). *indicates material for which sequences were obtained from NCBI GenBank. Material that was included in the final combined dataset is highlighted with bold morph codes (last column).

These values are somewhat dissimilar from those measured in waters in the Kisangani area (09-032; $\mathrm{pH} \sim 6.0-7.0$; $\mathrm{T}=\sim 24^{\circ} \mathrm{C}$, conductivity $\left.\sim 70 \mu \mathrm{S} / \mathrm{cm}\right)$.

\section{Morphological characterization}

Melanoides specimens were identified based on shell morphology using the relevant literature [30,31]. Shell morphology was studied directly and after cleaning with bleach. Morphological comparisons were performed independently by B.V.B. and C.C. using a modified version (1 extra trait, some additional trait values) of the categorical shell-morphological character scoring system of Facon et al. [20]. Modifications allow coding the sampled endemic Melanoides species of the DRC for comparison. As mentioned, the predominantly parthenogenetic reproduction of $M$. tuberculata usually results in limited intrapopulation variation in shell morphology [18]. Discrete morphs can hence be recognized and the morphological scoring system is considered to be generally robust for delimiting parthenogenetic lineages of $M$. tuberculata, although closely related morphs occasionally display strikingly different shell features $[20,21]$. Characters with multiple states were converted to arithmetic means and morphological scores were converted into a distance matrix that was ordinated with non-metric multidimensional scaling (nmMDS) in three dimensions following the guidelines of Van Bocxlaer and Schultheiß [32]. We used the packages MASS version 7.3-27 [33] and vegan version 2.0-10 [34] in $\mathrm{R}$ version 3.0.1 [35] for nmMDS.

\section{Phylogenetic analyses}

Genomic DNA was isolated using the CTAB protocol [36]. Two gene markers were used: (1) mitochondrial cytochrome $c$ oxidase subunit I (COI), and the (2) mitochondrial large ribosomal subunit (mtLSU rRNA or 16S). DNA, specimen and image vouchers of newly sequenced material (49 specimens) were deposited at the Justus Liebig University's Systematics and Biodiversity collection (UGSB); data on other specimens (59 COI and $3716 \mathrm{~S}$ sequences) was retrieved from NCBI GenBank (Table 1).

COI sequences were obtained utilizing the forward primer LCO1490 [37], and the reverse primers HCO2198 [37] or COX-B7R [38]. For amplification of partial 16S DNA we used the forward and reverse primers (16Sar-L and 16SbrH) from Palumbi et al. [39]. PCR cycling conditions are specified in Additional file 1: Table S1. Bidirectional DNA sequencing was performed on a 16-capillary $3730 x l$ Genetic Analyzer (Applied Biosystems). New sequences were deposited in GenBank (Table 1). The first basepairs (bp) behind the 3' end of each primer were difficult to read. We therefore trimmed each sequence, leaving a 580 bp-long overlapping COI fragment and a 451-455 bp-long 16S fragment. The protein-coding COI sequences were unambiguously aligned using ClustalW implemented in BioEdit 7.0.8.0 [40]. We aligned 16S fragments using the multiple sequence alignment program PRANK [41] with empirical base frequencies, the Tamura-Nei substitution model and default settings for gap penalties. Ambiguously aligned sites (posterior probability of the obtained structure state $\leq 0.8$ ) were excluded from subsequent analyses. Inclusion of unknown states for shorter $16 \mathrm{~S}$ fragments obtained from 


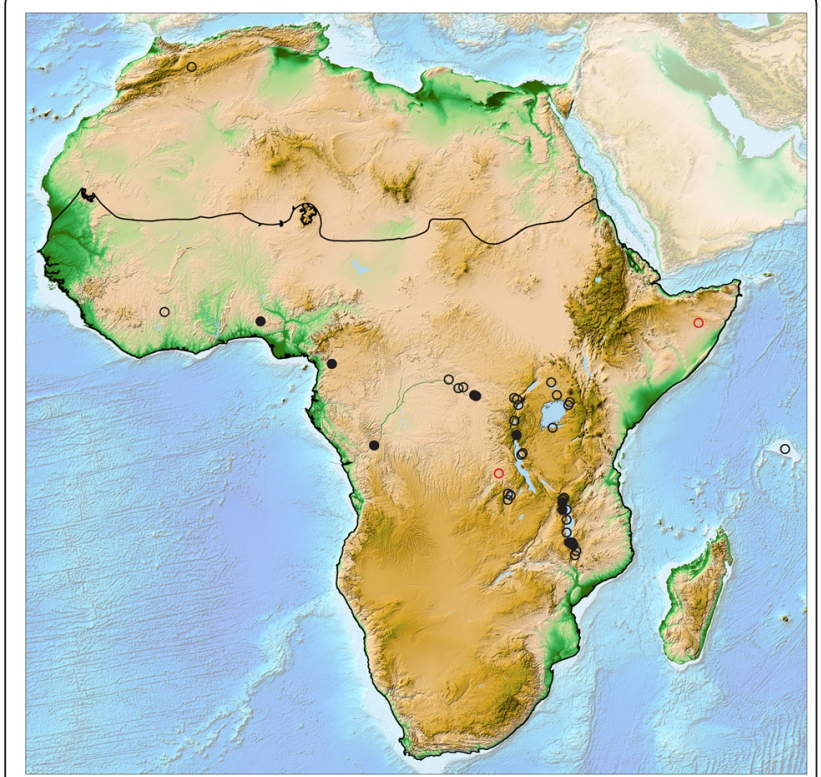

Figure 1 Map of Africa with localities of Melanoides

populations included in our study. The genus occurs in a wide variety of water bodies throughout Africa (rivers, ponds, lakes), but is absent from substantial areas, e.g. in the Sahara it has scattered occurrences in oasis lakes. Solid symbols indicate invasive $M$. tuberculata populations, open ones native Melanoides populations.

Two red symbols indicate approximate localities of GenBank

material. A solid black line delimits sub-Saharan Africa as defined for modeling purposes following [28]. Map modified from Amante and Eakins [29].

GenBank caused alignment problems and the deletion of $70 \mathrm{bp}$, many of which were informative. Therefore, we decided to drop these shorter-fragment sequences from our dataset $(n=21$; Table 1$)$, resulting in a 452 bp long $16 \mathrm{~S}$ alignment for 63 haplotypes.

No substantial substitutional saturation was found in the COI and $16 \mathrm{~S}$ datasets upon testing with DAMBE version 5.2.73 [42]. The final dataset $(\mathrm{COI}+16 \mathrm{~S})$ contained a total of 79 unique sequences (including one of Thiara scabra, four of Tarebia granifera, and the outgroup taxa Hydrobia glyca and Lavigeria grandis; see Table 1). Substitution models were examined for individual partitions with jModelTest 0.1.1 [43] using corrected Akaike and Bayesian Information Criteria (AICc and BIC, respectively). The best supported substitution model for the COI dataset was HKY + I + G (AICc and $\mathrm{BIC}$ ) and for the $16 \mathrm{~S}$ alignment GTR + G (AICc) or HKY (+ I) + G (BIC; same support with or without invariant sites). The concatenated dataset was analyzed in BEAST version 1.7.4 [44] using a Yule speciation process, a total of 40,000,000 generations (with sampling each 1,000th generation), and a burn-in of 20,001. Independent phylogenetic analyses were performed using strict and uncorrelated lognormal relaxed clock models (with 1.0 as relative rate). Effective sample size (ESS) values of all major parameters within the BEAST analyses were visualized and checked in Tracer version 1.5.0 [44]. These checks demonstrated that the ESS values for 'prior' and 'posterior' were unacceptably low when the GTR + G model was used for the $16 \mathrm{~S}$ partition, which may indicate that the model was overparameterized. Hence, we decided to use the still well-supported but less complex HKY $+\mathrm{I}+\mathrm{G}$ model for each partition in the concatenated dataset which produced good ESS values (>200) for all parameters. Bayes Factor (BF) analysis was performed in Tracer and likelihood values based on 1,000 bootstrap replicates were evaluated to select the appropriate clock model (following criteria of Kass and Raftery [45] and Suchard et al. [46]). To examine potential conflicts among the COI and $16 \mathrm{~S}$ partitions each dataset was also analyzed individually in BEAST following the conditions described above (e.g. HKY + I + G model).

To examine invasions and to get a better insight into the geographic distribution of the ingroup taxa we performed ancestral range reconstructions with the concatenated COI $+16 \mathrm{~S}$ dataset. For transparency and to avoid circularity we only included actual occurrences of the terminal taxa in the dataset, regardless of whether the material is known to be invasive in the area of occurrence. For example, specimens from the Neotropics are coded as American, even though the specimens represent well-documented Asian invasions $[17,20]$. Analyses were performed in R using the packages ape 3.1-4 [47] and geiger 2.0.3 [48], and independently with Lagrange version 20130526 [49]. For the first, regions were coded and states were reconstructed using maximum likelihood estimation and marginal reconstruction. For Lagrange a presence-absence matrix was created and combined with the phylogeny in the Lagrange configurator (http://www. reelab.net/lagrange/configurator/index) to create the input file, which was analyzed using default settings.

\section{Geographical modeling}

Anthropogenic influences on the colonization history of invasive M. tuberculata in Africa were assessed with spatial modeling. We used human population size as a proxy of the variety of anthropogenic effects, e.g. human-mediated dispersal and anthropogenic changes in habitats (pollution, use of natural resources, and climate change), that humans have on natural environments in a particular region. Specifically, we investigated the null hypothesis that localities with recorded invasions represent a random sample with respect to human population. We used NASA SEDAC's gridded population of the World data (GPWv3; count data, estimates for 2010) [50] with a spatial resolution of $\sim 21 \mathrm{~km}^{2}$, and extracted data for sub-Saharan Africa (as defined in [28]) as an estimator of anthropogenic stressors. We compared human population counts for cells where invasive 
Melanoides specimens are recorded to the counts for all grid cells $(n=988,224)$ and assessed the probability of observed patterns in two ways. First, we divided all grid cells in two groups; the first group contains all cells where human population counts are smaller than the minimum count in grid cells with invasive gastropods; the second group has all counts higher than this minimum. We then calculated the statistical chance for the observed number of invasions to occur in the grid cells where they were observed assuming human population density is not affecting invasions. Second, we drew 10,000 random samples of grid cells from sub-Saharan Africa, each with a size equal to the number of grid cells with observed invasions and summed the human population counts of these grid cells. With these random samples we built a frequency distribution against which we plotted the summed human population counts from grid cells with invasions. Spatial modeling was performed in R 3.0.1 using the packages raster 2.2-31 [51], rgdal 0.9-1 [52], dismo 0.9-3 [53] and MASS.

\section{Systematics}

The nominal, endemic Melanoides species of Lake Malawi have been aggregated by some authors $[22,54]$ into a ' $M$. polymorpha complex', even though distinct morphs can be discerned in the modern [31,55] and fossil faunas of Lake Malawi [56]. We have not altered previous assignments of specimens in GenBank, but consider the traditional species valid until a formal taxonomic revision demonstrates otherwise.

\section{Results}

\section{Phylogenetic analysis}

Phylogenetic analyses of the concatenated COI $+16 \mathrm{~S}$ dataset (Figure 2) resulted in overall highly similar topologies to those in single fragment phylogenies (Figure 3), despite substantial differences in the sampling for both genes (Table 1). Analyses of BF revealed that the fit of uncorrelated lognormal relaxed clock models to our datasets was consistently better than that of strict clock approaches, and hence uniform rates of sequence evolution along the phylogeny were rejected. Ancestral range reconstructions in $\mathrm{R}$ and using Lagrange resulted in almost identical results; the first method was used for visualization; results of the second method are displayed in Additional file 2: Table S2.

Phylogenetic inference revealed a split between two clades of Melanoides species (Figures 2 and 3), both of which have occurrences on Africa and Asia. One of these clades (clade 1) contains predominantly endemic taxa from Lakes Malawi and Mweru and the Congo Basin, a sub-clade of Asian M. tuberculata, and Tarebia granifera; the other clade (clade 2) contains taxa endemic to the Congo Basin, other morphs of $M$. tuberculata and Thiara scabra (Figure 2). Our phylogeny hence indicates that Melanoides is paraphyletic, as Thiara scabra and Tarebia granifera cluster within Melanoides clades (Figure 2). Moreover, Melanoides tuberculata, and interestingly also the African endemic Melanoides species were found to be polyphyletic.

Phylogenetic reconstruction (Figure 2) reveals the occurrence of an invasive Asian morph of $M$. tuberculata in the Kisangani area (DRC) that is closely related to the LMI morphs from Lake Malawi (with a basal Bayesian Posterior Probability [BPP] support of 1.00). The invasive nature of this clade is well-supported by the ancestral range reconstruction of clade 5, certainly upon considering external evidence that American taxa within this clade represent historical Asian invasions. For consistency with the literature [17,20-22] we propose CDI as the three-letter code for this morph. Whereas some molecular variability exists in COI sequences of the LMI morphs from Lake Malawi, specimens from 5 populations of morph CDI have identical COI sequences. This CDI morph was found in 4 small rivers and swamps that discharge directly or indirectly to the Congo River and that encompass an area of 150 $\mathrm{km}^{2}$ (Additional file 3: Table S3). Another independent Asian invader has been sampled from Lake Tanganyika near Bujumbura (again with $\mathrm{BPP}=1.00$ ), and belongs to clade 2 (morph BIT; Figure 2). The invasive nature of this morph is again well-supported by ancestral range reconstructions. No Asian invasions were discovered thus far upon screening samples from the Nile drainage (Table 1). Ancestral range reconstructions for the entire ingroup suggested that an African origin is most likely.

Our phylogeny also revealed a close and strongly supported (BPP of 1.00) relationship between endemic Melanoides species from the Lower Congo River (downstream of Kisangani) and M. admirabilis from the Malagarasi River at the base of clade 2 (Figure 2).

\section{Experimental and morphological data}

Freshly collected Melanoides specimens from the Kisangani area have a very conspicuous dark-brown to black organic coating that masks most shell features. Upon bleaching, wild-caught individuals of morph CDI displayed more variability in shell features than did the LMI specimens from Lake Malawi as reported by Genner et al. [21], but lab-bred $F 1$ specimens of morph CDI $(n=10)$ did not and resemble these LMI morphs strikingly (Figure 4, Table 2). A columellar band is usually present in LMI morphs [21] but it is often absent in specimens of morph CDI, and whereas axial ribs were reported to be absent in LMI, they are regularly present on juvenile whorls in CDI, albeit shallow (Table 2). All wild-caught individuals from population 09-032 that we examined lacked a columellar band and some had axial 


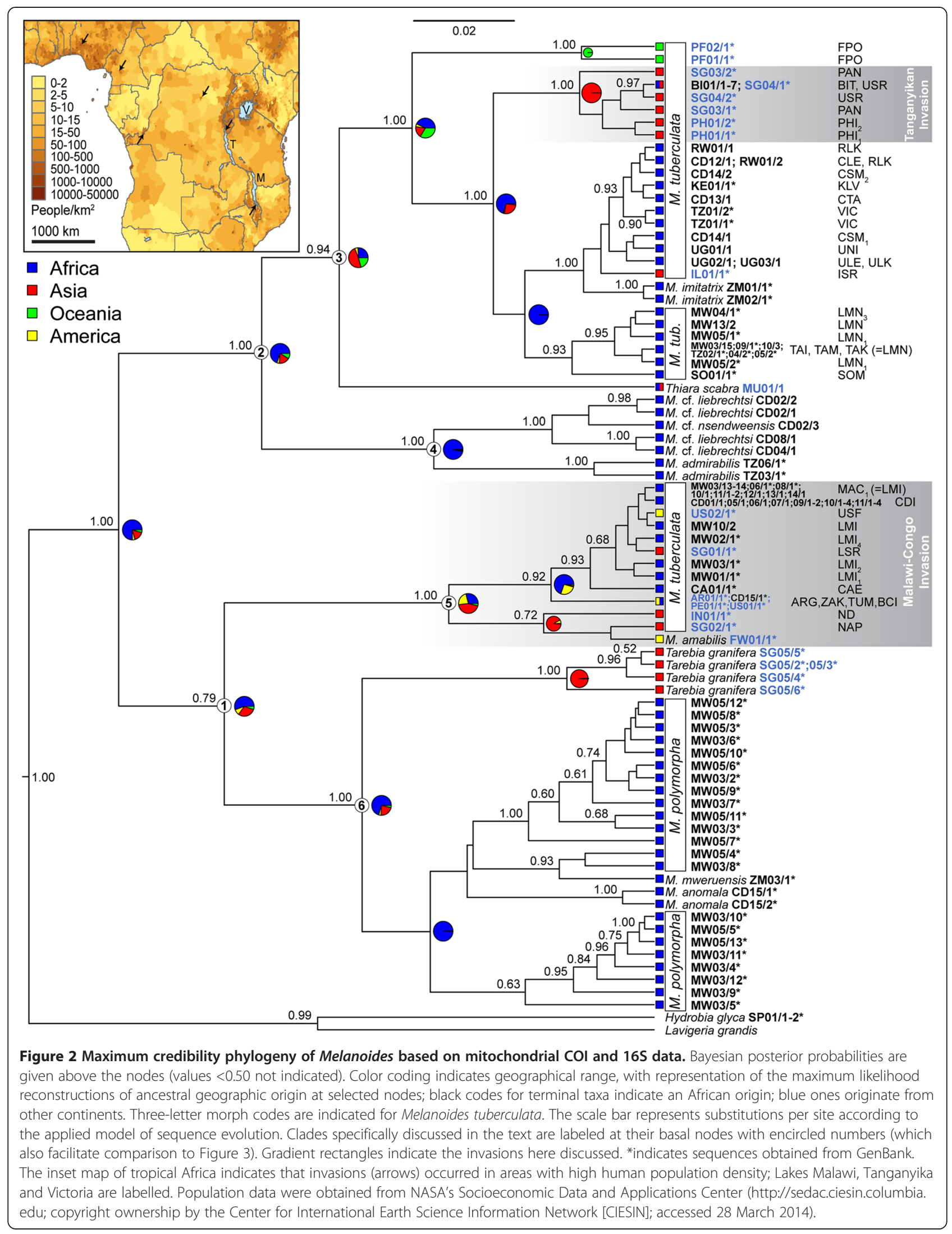




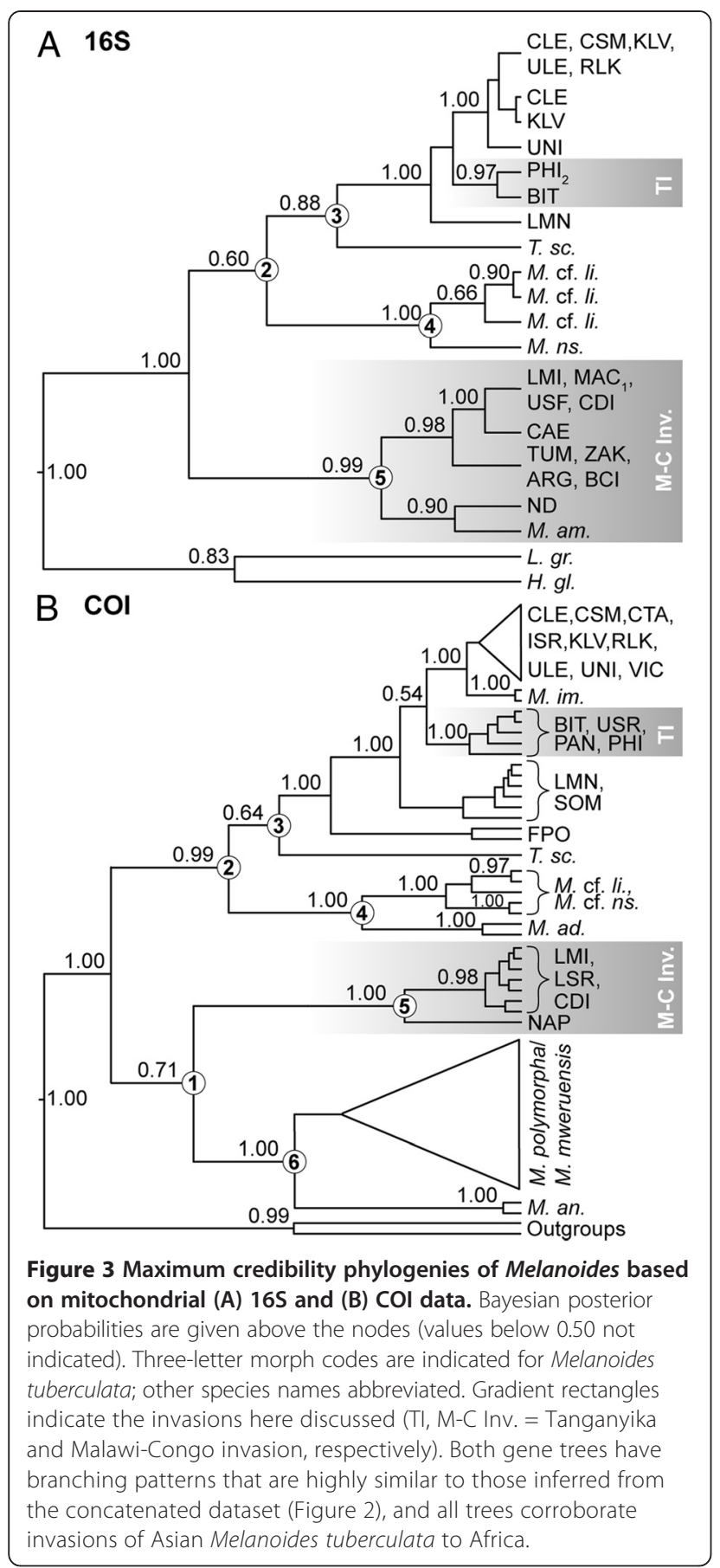

ribs (Table 2), but the band was faintly present on labbred $F 1$ offspring of the population, which lacked axial sculpture, even on juvenile whorls (Figure 4F).

Ordination of morphological characters of native and invasive $M$. tuberculata in morphospace resulted in limited stress (8.99), which suggests a reliable ordination result. This result confirmed the observations mentioned above (Figure 5) and that the invasive BIT morph of $M$. tuberculata displays limited morphological variability in comparison to CDI and LMI morphs. On a continental scale, an overlap exists in morphological variation displayed by native and invasive $M$. tuberculata morphs (Figure 5), although some of the overlapping populations belong to deeply divergent clades (Figure 2).

\section{Geographical modeling}

Invasive lineages of Melanoides tuberculata were documented from 6 major localities in 5 countries (Ede, Nigeria; Eseka, Cameroon; Kinshasa, Kisangani, DR Congo; Bujumbura, Burundi; Monkey Bay/Cape Maclear, Malawi). At $>500$ people $/ \mathrm{km}^{2}$, all these localities are densely populated. To be conservative, we divided grid cells into a group with more, and one with less than 100 people $/ \mathrm{km}^{2}$. Adjusted to the spatial scale of the NASA human population grid this resulted in 76,391 and 911,833 cells in the first and second groups, respectively. The probability that the 6 localities with invasions represent a random sample with respect to human population density is very small $(p=2.13 \mathrm{e}-07)$. Comparing the sum of human population counts from the grid cells where invasions were observed ( 257,000 people) to the frequency distribution of summed human population counts from randomly selected grid cells in sub-Saharan Africa resulted in 2 out of 10,000 simulations having counts higher than observed (Figure 6). Modeling results indicate that colonization was non-random and mainly in highly populated, and hence anthropogenically disturbed areas.

\section{Discussion}

\section{Reliability of phylogenetic data}

Previous authors reported major incongruences between COI and $16 \mathrm{~S}$ datasets, which prevented them from combining fragments into a concatenated analysis [22]. Inclusion of more specimens, sequencing of longer $16 \mathrm{~S}$ fragments, and the use of more advanced software for alignment and phylogenetic inference (see methods) removed this incongruence (Figures 2 and 3). The branching pattern of major clades and the documentation of some lineages as invasive were consistently recovered.

\section{Phylogenetic patterns and biogeographic affinities}

Phylogenetic analyses confirmed that Melanoides is paraphyletic and M. tuberculata polyphyletic [54], but interestingly, also the African endemic Melanoides species were revealed to be polyphyletic. Taxa endemic to Lakes Malawi and Mweru and the Lualaba River are part of clade 6, whereas others distributed more to the north in the Congo and Malagarasi Rivers belong to clade 4 . As is the case for viviparids [57], the Congo system appears to play an important role in shaping biogeographical patterns for Melanoides species endemic to Africa, but additional sampling is required to evaluate 


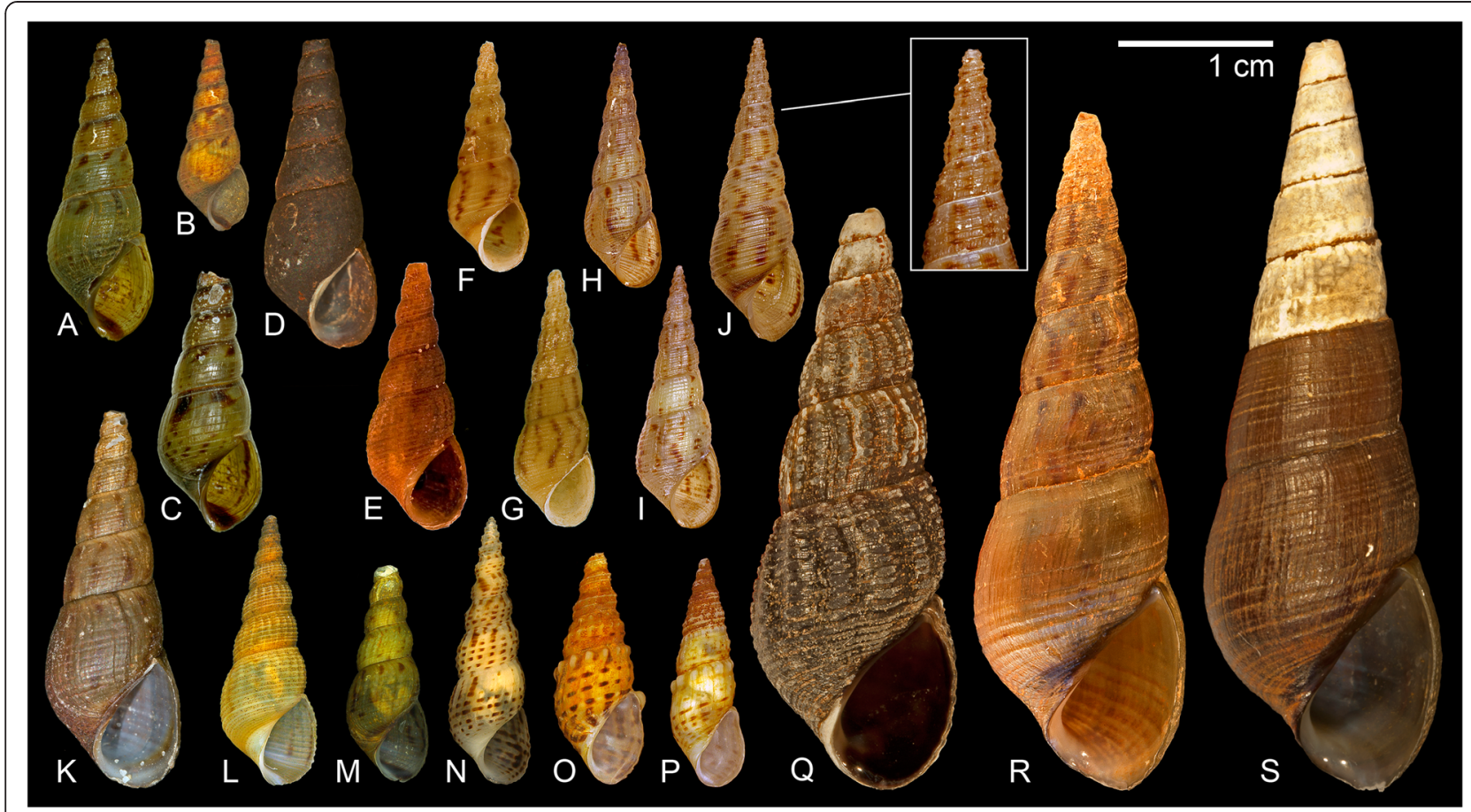

Figure 4 Morphology of Melanoides morphs: A-C) invasive M. tuberculata morph BIT from Lake Tanganyika (BI01); D-E) wild type of M. tuberculata morph CDI from the Congo River at Kisangani with organic coating (D: DRC09-033; E: DRC09-032); F) Lab-bred F1 CDI specimen from population CD06 (4 months old); G-I) invasive M. tuberculata morph LMI from Chipoka at Lake Malawi (G: BVB-ML-08; H-I: UGSB 0138 [note that $\mathrm{H}-\mathrm{I}$ lack a columellar band and have axial sculpture]); J) morph LMl from the Shire River with columellar band and axial sculpture (UGSB 1246); K-M) bleach-cleaned CDI specimens (K: CD05; L: CD10; $\mathbf{M : ~ C D 0 7 ) ; ~ N ) ~ n a t i v e ~ M . ~ t u b e r c u l a t a ~ f r o m ~ L a k e ~ E d w a r d ~ ( C D 1 2 ) ; ~ O - P ) ~ t o ~ t h e ~ C o n g o ~ B a s i n ~}$ endemic M. cf. liebrechtsi (O: CD02; P: CD08); Q) native M. tuberculata morph LMN from Monkey Bay at Lake Malawi (UGSB 0183); R-S) non-parasitized giants of the morph LMI from the same locality as Q (UGSB 0183).

similarities in the patterns of both taxa. Scrutinity is required to evaluate the position of M. imitatrix [54], and our phylogenetic reconstruction indicates a general need for more phylogenetic work (including nuclear markers) and taxonomic revisions of the genus Melanoides. Such revisions will ideally integrate molecular, conchological and anatomical analyses (see below).

Clades 1 and 2 of our phylogeny both contain Asian and African Melanoides species, with different degrees of molecular divergence (Figure 2). Earlier authors [18,22,54] have suggested that the genus Melanoides probably has an African origin, and ancestral range reconstructions confirm the likelihood of this scenario.

The close and highly supported phylogenetic relationship of M. admirabilis from Tanzania and endemic $\mathrm{Mel}$ anoides species from the Congo River (Figures 1 and 2), i.e. between gastropods from rivers flowing into and out of Lake Tanganyika, indicate the historic connection of biological provinces east and west of this lake. Close affinities of Malagarasi and Congo River mollusks have been suggested before, e.g. for Potadomoides [58], but we present the first molecular evidence for this hypothesis. Molecular evidence supporting close phylogenetic relationships also exists in Congo and Malagarasi fishes
[59-61]. However, fish faunas of Lake Tanganyika appear to have seeded the fauna of the lake's tributaries and outflow to a larger extent [60] than appears the case for mollusks [62,63]. The pattern of basin endemism and close genealogical relationships between taxa that occupy the same drainage basin also suggests that the dispersal capacities of the native, endemic Melanoides species are more restricted than those of the invasive $M$. tuberculata morphs. Moreover, the phylogenetic relationships between freshwater biota in the Malagarasi River and the Congo River and the independent Melanoides invasions to Lake Malawi and Lake Tanganyika provide testimony that the ecosystems of long-lived African lakes are permeable, at least periodically, to more widespread biota; see [62].

\section{Multiple invasions of $M$. tuberculata to Africa}

Our phylogeny revealed that two deeply divergent clades of invasive, Asian M. tuberculata have contributed to the taxon's continent-wide invasion of Africa (Figures 1 and 2). An invasive $M$. tuberculata morph (CDI) occurs in the Congo Basin, some 1,500 km away from the Malawi Basin, which is occupied by closely related invasive morphs $\left(\mathrm{LMI}_{1-4}\right)$. These morphs are very closely related to two other morphs from 
Table 2 Categorical description of Melanoides species/morphs based on shell morphology using an expanded version of the scoring system of Facon et al. [20]

\begin{tabular}{|c|c|c|c|c|c|c|c|c|c|c|c|c|c|c|c|c|}
\hline \multirow[b]{2}{*}{ Species } & \multirow[b]{2}{*}{ Population code } & \multicolumn{3}{|c|}{ Background colour } & \multicolumn{4}{|c|}{ Colour patterns } & \multicolumn{2}{|c|}{ Columellar band } & \multicolumn{2}{|c|}{ General shape } & \multicolumn{4}{|c|}{ Sculpture } \\
\hline & & IN & TI & HE & DO & SP & so & $\mathrm{HO}$ & SH & SC & $\mathrm{CO}$ & RO & GR & $C D$ & RI & RD \\
\hline \multicolumn{17}{|l|}{ Clade 1} \\
\hline M. tuberculata & $\mathrm{CD} 01 / 1^{1}$ & 4 & 5 & 0 & 0 & na & na & na & 1 & na & 1 & 2 & 2 & 0 & 3 & 1 \\
\hline M. tuberculata & CD01-A & 2 & 2 & 0 & 2 & 2 & 3 & 1 & 2 & 2 & 1 & 2 & 2 & 0 & 1 & 1 \\
\hline M. tuberculata & CD01-B & 2 & 4 & 0 & 2 & 1 & 2 & 1 & 1 & na & 1 & 2 & 2 & 0 & 3 & 1 \\
\hline M. tuberculata & CD05-A & 1 & 4 & 0 & 1 & 1 & 2 & 1 & 1 & na & 1 & 2 & 2 & 0 & 3 & 1 \\
\hline M. tuberculata & CD05-B & 2 & 1 & 0 & 2 & 1 & 2 & 1 & 1 & na & 1 & 2 & 1 & 0 & 0 & na \\
\hline M. tuberculata & CD06-A & 1 & 4 & 0 & 1 & 2 & 1,2 & 1 & 1 & na & 1 & 2 & 2 & 0 & 3 & 1 \\
\hline M. tuberculata & CD06-B & 2 & 1 & 0 & 1 & 2 & 1,2 & 1 & 1 & na & 1 & 2 & 1 & 0 & 0 & na \\
\hline M. tuberculata & CD05-06 F1 & 2,3 & 1 & 0 & 2 & 2 & 2 & 1 & 2 & 2 & 1 & 2 & 2 & 0 & 0 & na \\
\hline M. tuberculata & CD07-A & 2 & 2 & 0 & 1 & 2 & 2 & 2 & 2 & 1 & 1 & 3 & 1 & 0 & 3 & 1 \\
\hline M. tuberculata & CD07-B & 2,3 & 1 & 0 & 1 & 1 & 2 & 1 & 1 & na & 1 & 3 & 1 & 0 & 0 & na \\
\hline M. tuberculata & CD09-A & 3 & 1 & 0 & 1 & 2 & 1 & 1 & 1 & na & 1 & 2 & 1 & 0 & 3 & 1 \\
\hline M. tuberculata & CD09-B & 2 & 1 & 0 & 1 & 2 & 2 & 1 & 2 & 2 & 1 & 2 & 1 & 0 & 1 & 1 \\
\hline M. tuberculata & CD10/1-4 & 4 & 5 & 0 & 0 & na & na & na & 1 & na & 1 & 2 & 3 & 0 & 3 & 2, \\
\hline M. tuberculata & CD10-A & 2 & 1 & 0 & 0 & na & na & na & 2 & 2 & 1 & 3 & 2 & 0 & 3 & 2 \\
\hline M. tuberculata & CD10-B & 2 & 4 & 0 & 1 & 2 & 1 & 1 & 1 & na & 1 & 3 & 2 & 0 & 3 & 2 \\
\hline M. tuberculata & CD11/1-4 & 4 & 5 & 0 & 0 & na & na & na & 1 & na & 1 & 2 & 2 & 0 & 0 & na \\
\hline M. tuberculata & $\mathrm{LMI}_{1}^{2}$ & 2 & 1 & 0 & 2 & 2 & 2 & 1 & 2 & 2 & 1 & 2 & 2 & 0 & 0 & na \\
\hline M. tuberculata & $\mathrm{LMI}_{2}^{2}$ & 2 & 2 & 0 & 2 & 2 & 2 & 1 & 2 & 2 & 1 & 2 & 2 & 0 & 0 & na \\
\hline M. tuberculata & $\mathrm{LMI}_{3}^{2}$ & 3 & 2 & 0 & 2 & 2 & 3 & 1 & 3 & 3 & 1 & 3 & 2 & 0 & 0 & na \\
\hline M. tuberculata & $\mathrm{LMI}_{4}^{2}$ & 2 & 1 & 0 & 2 & 2 & 3 & 1 & 3 & 3 & 1 & 2 & 2 & 0 & 0 & na \\
\hline M. tuberculata & MW11/1 & 3 & 2 & 0 & 2 & 2 & 2 & 1 & 1 & na & 1 & 2 & 2 & 0 & 1 & 1 \\
\hline M. tuberculata & MW12/1 & 3 & 2 & 0 & 2 & 2 & 2 & 1 & 2 & 2 & 1 & 2 & 2 & 0 & 1 & 1 \\
\hline
\end{tabular}

Clade 2

$\begin{array}{lllllllllllllllll}\text { M. cf. liebrechtsi } & \text { CD02/1 } & 3 & 1 & 0 & 2 & 2 & 2 & 2 & 1 & \text { na } & 2 & 2 & 2 & 2 & 2 & 1 \\ \text { M. cf. liebrechtsi } & \text { CD02/2 } & 3 & 1 & 0 & 2 & 2 & 2 & 2 & 1 & \text { na } & 2 & 2 & 2 & 2 & 2 & 2 \\ \text { M. cf. nsendweensis } & \text { CD02/3 } & 2 & 1 & 0 & 0 & \text { na } & \text { na } & \text { na } & 1 & \text { na } & 3 & 1 & 2 & 0 & 2 & 2 \\ \text { M. cf. liebrechtsi } & \text { CD03/1 } & 2 & 1 & 0 & 1 & 2 & 2 & 2 & 1 & \text { na } & 2 & 2 & 2,3 & 0 & 1 & 1 \\ \text { M. cf. liebrechtsi } & \text { CD03-A } & 2 & 1 & 0 & 2 & 2 & 1 & 2 & 1 & \text { na } & 2 & 2 & 2,3 & 2 & 2 & 2 \\ \text { M. cf. liebrechtsi } & \text { CD03-B } & 3 & 1 & 0 & 2 & 2 & 2 & 2 & 1 & \text { na } & 2 & 1,2 & 2 & 2 & 2 & 1 \\ \text { M. cf. liebrechtsi } & \text { CD04/1 } & 2 & 1 & 0 & 2 & 2 & 2 & 2 & 1 & \text { na } & 2 & 2 & 2 & 2 & 2 & 2 \\ \text { M. cf. liebrechtsi } & \text { CD04-A } & 2 & 1 & 0 & 1 & 2 & 1 & 2 & 1 & \text { na } & 2 & 2 & 2 & 2 & 2 & 2 \\ \text { M. cf. liebrechtsi } & \text { CD04-B } & 2 & 1 & 0 & 2 & 2 & 2 & 2,3 & 1 & \text { na } & 2 & 2 & 2 & 2 & 2 & 2 \\ \text { M. cf. liebrechtsi } & \text { CD08-A } & 1 & 4 & 0 & 1 & 3 & 2 & 2 & 1 & \text { na } & 1 & 2 & 1 & 3 & 2 & 2 \\ \text { M. cf. liebrechtsi } & \text { CD08-B } & 1 & 4 & 0 & 1 & 2 & 2 & 2 & 1 & \text { na } & 1 & 2 & 1,2 & 3 & 2 & 1,2 \\ \text { M. tuberculata } & \text { BI01/1 } & 2,3 & 1 & 1 & 1 & 1 & 2 & 3 & 2 & 2 & 1 & 2 & 1 & 0 & 3 & 1 \\ \text { M. tuberculata } & \text { BI01/2 } & 2 & 2 & 1 & 1 & 1 & 2 & 3 & 2 & 3 & 1 & 2 & 1 & 0 & 3 & 1 \\ \text { M. tuberculata } & \text { BI01/3 } & 3 & 2 & 1 & 1 & 1 & 2 & 3 & 2 & 3 & 1 & 2 & 1 & 0 & 3 & 1 \\ \text { M. tuberculata } & \text { BI01/4 } & 2 & 2 & 1 & 1 & 1 & 2 & 3 & 2 & 2 & 1 & 2 & 1 & 0 & 3 & 1 \\ \text { M. tuberculata } & \text { MW10/3 } & 4 & 5 & 0 & 0 & \text { na } & \text { na } & \text { na } & 1 & \text { na } & 3 & 3 & 3 & 0 & 2 & 3 \\ \text { M. tuberculata } & \text { MW13/2 } & 3 & 1 & 0 & 2 & 2 & 1 & 2 & 1 & \text { na } & 2 & 3 & 3 & 0 & 3 & 3 \\ \text { M. tuberculata } & \text { MW13-A } & 2 & 1 & 0 & 0 & \text { na } & \text { na } & \text { na } & 1 & \text { na } & 2 & 2 & 3 & 0 & 3 & 3\end{array}$


Table 2 Categorical description of Melanoides species/morphs based on shell morphology using an expanded version of the scoring system of Facon et al. [20] (Continued)

\begin{tabular}{|c|c|c|c|c|c|c|c|c|c|c|c|c|c|c|c|c|}
\hline M. tuberculata & RW01/1 & 1 & 1 & 0 & 0 & na & na & na & 1 & na & 2 & 3 & 3 & 0 & 3 & 3 \\
\hline M. tuberculata & RW01/2 & 2 & 1 & 1 & 2 & 2 & 2 & 3 & 1 & na & 2 & 2 & 2 & 0 & 1 & 1 \\
\hline M. tuberculata & UG01/1 & 2,3 & 1 & 0 & 2 & 2 & 2 & 1 & 3 & 2 & 1 & 3 & 3 & 0 & 2 & 3 \\
\hline M. tuberculata & UG02/1 & 3 & 1 & 0 & 1 & 2 & 1 & 1 & 1 & na & 1 & 2 & 2 & 0 & 3 & 1 \\
\hline M. tuberculata & UG03/1 & 3 & 1 & 1 & 2 & 2 & 1 & 2 & 2 & 2 & 1 & 2,3 & 2 & 0 & 1 & 1 \\
\hline M. tuberculata & CD12/1 & 3 & 1 & 0 & 2 & 1 & 3 & 1 & 1 & na & 1 & 3 & 2 & 0 & 3 & 1 \\
\hline M. tuberculata & CD13/1 & 3 & 1 & 1 & 1 & 2 & 2 & 2 & 1 & na & 1 & 2 & 1 & 0 & 3 & 1 \\
\hline M. tuberculata & CD14/1 & 1 & 1 & 0 & 1 & 2 & 2 & 2 & 1 & na & 2 & 2 & 1 & 0 & 3 & 1 \\
\hline M. tuberculata & CD14/2 & 2 & 1 & 0 & 2 & 2 & 2 & 2 & 2 & 1 & 1 & 3 & 2 & 0 & 3 & 2 \\
\hline
\end{tabular}

Specimens were selected to cover the variation observed in populations. If the actual trait is on the border between two values (coded differently by the independent examiners), both values are indicated. Material indicated with a ${ }^{1}$ in the population code column was not bleached and reveals the actual appearance in the field; ${ }^{2}$ reflects assessments by Genner et al. [21].

Character explanation:

IN = intensity of the shell background color: (1) very pale, (2) pale, (3) medium, (4) dark.

$\mathrm{TI}=$ background tint of the shell: (1) yellow to brown, (2) greenish, (3) orange to reddish, (4) white, (5) brown to black.

$\mathrm{HE}=$ heterogeneity of the background color among different parts of a shell whorl: (0) homogeneous, (1) a distinctly darker band below the suture.

$\mathrm{DO}=$ overall density of reddish-brown color patterning on the whole shell, except the zone just below the sutures: (0) no patterning, (1) medium, (2) dense.

$\mathrm{SP}=$ type of patterning, expressed as the proportion of spots vs. flames: (0) only flames, (1) more flames than spots, (2) more spots than flames, (3) only spots. SO = size of the individual spots/flames: (1) small spots/narrow flames, (2) medium, (3) large spots/wide flames.

$\mathrm{HO}=$ heterogeneity of color patterning among different parts of the whorl: (1) homogeneous, (2) slightly different patterns just below the sutures (i.e. in the subsutural zone), (3) strongly different patterns in the subsutural zone compared to those on the rest of the shell.

$\mathrm{SH}=$ presence and sharpness of a dark band on the axial edge of the aperture (columellar band) and along the base of the body whorl: (1) absent, (2) diffuse, (3) sharp.

SC = size of the dark band, when present: (1) narrow, (2) medium, (3) wide.

$\mathrm{CO}=$ conicity of the shell: (1) acute, (2) medium, (3) blunted cone.

$\mathrm{RO}=$ roundness of the body whorl: (1) flat, (2) slightly rounded, (3) well-rounded.

$\mathrm{GR}=$ spiral cords/grooves: (0) absent, (1) shallow grooves/weakly pronounced cords, (2) intermediate, (3) very deep grooves/strongly pronounced cords.

$C D$ = subsutural spiral cord: (0) similar to the other spiral cords, (1) pronounced/swollen, but smooth, (2) pronounced/swollen with nods, (3) similar to other spiral

cords but with large nods.

$\mathrm{RI}=$ density and width of axial ribs: (0) none, (1) a few narrow ribs, (2) a few large ribs, (3) many narrow ribs.

$\mathrm{RD}=$ depth of axial ribs when present: (1) shallow, (2) medium, (3) deep.

'na' indicates when the trait is not applicable.

Singapore (LSS, LSR) [21]. We cannot exclude that morph CDI invaded the Kisangani area directly via intercontinental transport from Asia, but given that the single CDI haplotype is shared with LMI populations successful dispersal of LMI specimens over hydrographic boundaries is more likely (which is also supported by ancestral range reconstructions). Other African representatives of this invasive clade (clade 5) are morphs CAE from Cameroon (Eseka), morph ZAK from the DRC (Kinshasa), and (not shown) morph ND from Nigeria (Ede) [20]. The molecular diversity in these African morphs suggests that multiple Asian representatives of clade 5 invaded Africa. Other morphs of clade 5 are invasive to America (morphs ARG from Argentina, TUM from Peru, $\mathrm{BCI}$ and USF from Florida, and M. amabilis from Martinique) and are genetically closely related to morphs with Asian origins, such as NAP from Singapore (Figure 2), morphs BAN and CHM from Thailand (Bangkok and Chiang-Mai, respectively; not shown), and morph ND from Indonesia (Lombok) [20,21]. These morphs (except for USF) are more distantly related to the CDI and LMI morphs, however. Another independent invasion occurred to Lake Tanganyika; this morph (BIT) is genetically nearly identical to morph USR from Singapore. Limited genetic diversity was observed within morphs CDI and BIT in comparison to that in invasive morphs from Lake Malawi, which suggests a single, potentially very recent, invasion for each of these morphs. Overall, our findings strongly indicate that multiple, independent invasions to Africa occurred, which may have resulted from increased aquarium trade [20,21]. Commercial activities with ornamental fish are reported for several of the localities where invasive $M$. tuberculata populations were recorded. More screening of other African Melanoides populations is required to fully document the geographic coverage of African invaders and the extent to which this coverage results from intercontinental introductions versus dispersal of invaders within Africa. Dispersal of LMI morphs to the north of Lake Malawi [22], to Lake Malombe [21], and further down the Shire River [24] suggests the morph will spread further through the Zambesi River system, and the occurrence of multiple CDI populations in various streams and ponds in the Kisangani area indicates that dispersal is ongoing there too.

\section{Morphological variation and ecophenotypy}

Interestingly, the Asian invasive lineages resemble eachother somewhat in overall shell morphology, although they belong to deeply divergent clades (Figure 5, compare e.g. Figure $4 \mathrm{~A}-\mathrm{C}$ with $4 \mathrm{M}$; Table 2). Moreover, our 


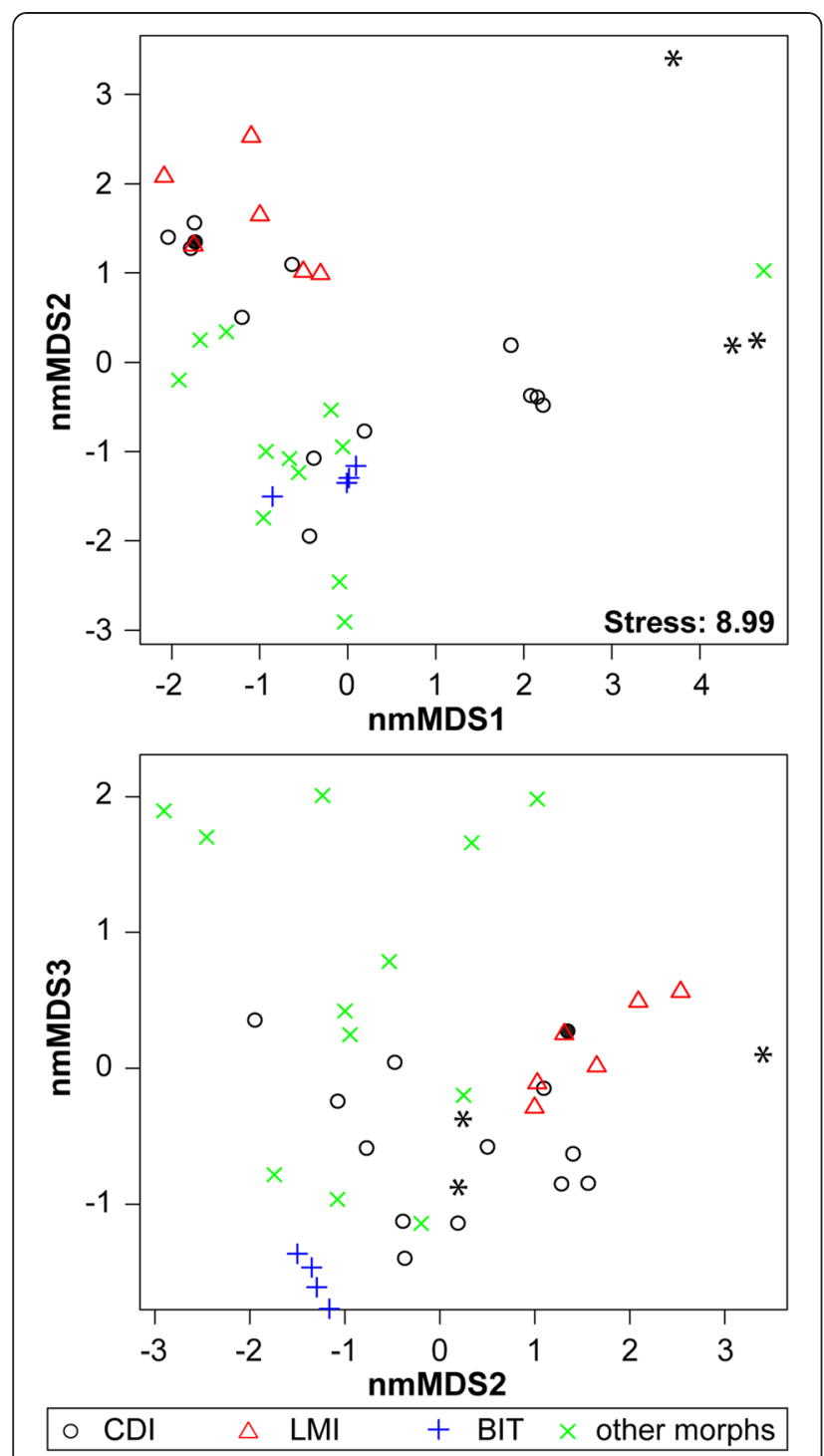

Figure 5 Non-metric multidimensional scaling of morphologically-scored, African Melanoides tuberculata populations. Morph codes are provided for invasive morphs, whereas native African morphs are lumped. Morphs CDI and LMI belong to clade 1, whereas all other material belongs to clade 2, illustrating that despite a deep phylogenetic split morphological overlap exists between both clades. Our study is the first to find morphological overlap between native and invasive $M$. tuberculata morphs, which hampers separating them based on shell morphology alone. The solid black circle indicates the position of lab-bred Fl individuals of morph CDI; * indicates the position of organically coated CDI specimens that were not bleached before assessment.

results document an overlap in the morphological variation of native and invasive $M$. tuberculata. This overlap does not exist for the invasive and native $M$. tuberculata from Lake Malawi [21], which may explain why these invasive populations were detected early on. Observations in the Malawi Basin may have raised the

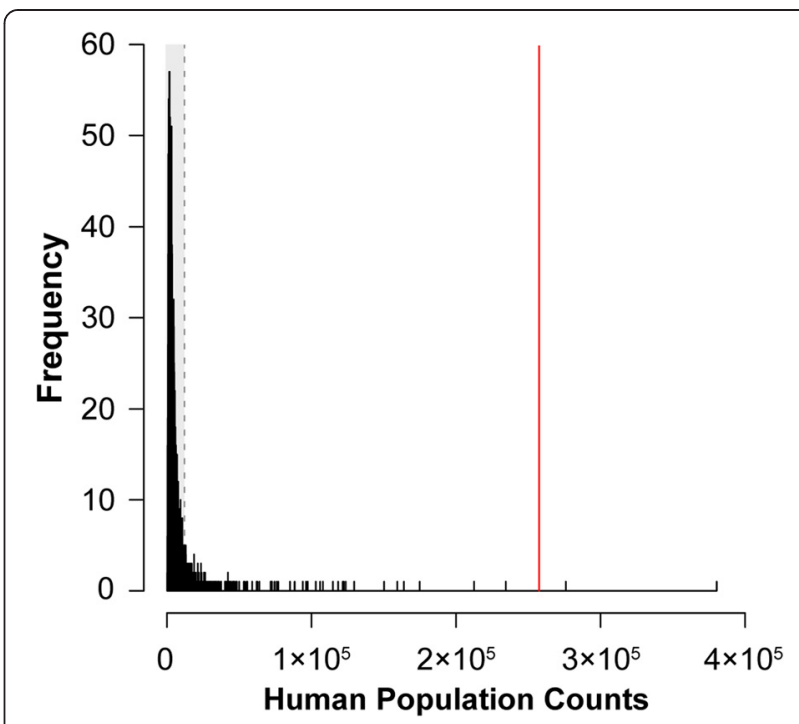

Figure 6 Frequency distribution of summed human population counts in 6 randomly selected grid cells in sub-Saharan Africa.

The distribution was constructed from 10,000 sampling runs and compared to the observed summed human population counts in the 6 grid cells where invasions were observed (red line). Grey zone indicates the $95 \%$ samples with lowest human population counts. Only 2 of the 10,000 random sampling runs resulted in sums higher than the observed value, suggesting that invasions were non-random with respect to human population (as a proxy for anthropogenically-induced stress).

expectancy that both groups can be separated easily. However, this expectancy does not hold on a continental scale; morphs belonging to clades 1 and 2 of our phylogeny (Figure 2) cannot be readily distinguished from one another using shell characters. The existence of morphological overlaps underscores the need for integrated molecular-morphological approaches to assess cryptic $M$. tuberculata invasions. Difficulties to identify genetic lineages based on morphological observations in the field currently hamper efforts aimed at conservation and they have contributed to the uncertain taxonomy of African Melanoides.

Unfortunately, some of the characters that were used to distinguish LMI morphs from the native LMN morphs of Lake Malawi (the presence of a columellar band and the absence of axial ribs; [21]) cannot be used to diagnose the closely related CDI morph from the Congo Basin. Further examination of LMI specimens from Lake Malawi confirmed that LMI morphs have become more variable in these features than originally reported (Table 2; see also [21,24]). Moreover, some LMI populations display gigantism (Figure $4 \mathrm{R}, \mathrm{S}$ ), which is mainly observed in LMN morphs following parasitic castration [23]. However, the LMI specimens were not parasitized. A consistent morphological feature of CDI and LMI morphs is their very sharp apical angle, which is usually also observed in BIT specimens (Figure 4). 
Although they have a genetic basis [18], shell features of the invasive $M$. tuberculata morphs are also subject to ecophenotypy. Differences in appearance relate partly to the organic layer that often covers shells, which may conceal differences between native and invasive $M$. tuberculata morphs (Table 2), and to actual shell morphology. The shell morphology of laboratory $F 1$ offspring of morph CDI resembles that of some LMI morphs from Lake Malawi more closely than the variable set of morphological features displayed by their parents (Table 2, Figure 5). This observation of marked phenotypic plasticity is somewhat surprising given the clonal reproduction, and that morphs of M. tuberculata are known to have colonized habitats halfway across the globe without morphological changes (e.g. morph PCD in Martinique and Japan; [17]). Morphological variation in wild-collected morph CDI, despite the lack of genetic diversity in the mitochondrial markers studied, is considerably larger than in LMI morphs (Figure 6), which hence confirms the great plasticity observed in experiments. More puzzling is that CDI individuals from the wild are usually coated with a thick organic layer that obscures most shell features. Perhaps morphological variation is correlated with other fitnessaffecting traits, rather than having a direct selective advantage.

Our data are consistent with the suggestion that phenotypic plasticity and genetic variation resulting from serial introductions enhance the dispersal capabilities of invasive taxa [15]. However, various signals are observed: the LMI morphs that are spreading throughout the Malawi Basin display some genetic variability but seemingly limited plasticity whereas the opposite is observed for the CDI morph spreading in the Kisangani area (Figures 2 and 5). More research is required to elucidate this pattern and to look into the effects of plasticity and genetic variation on the success of invasion and dispersal. Although observed differences may relate to differences in 'maturity' of invasive populations and differences in the time of arrival to Africa, LMI morphs do not appear to have displayed elevated ecophenotyic plasticity before. Despite ecophenotypic variation, the apical angle appears to be a good diagnostic feature to select putatively invasive populations for molecular screening.

\section{Ecosystem deterioration and invasiveness}

Eutrophication and pollution are known to increase the biomass of some opportunistic benthic mollusks including M. tuberculata [31,64]. Melanoides primarily inhabits sandy substrates [31], and it is perhaps not surprising that the invasive $M$. tuberculata strains were observed in areas of high anthropogenic disturbance. The Burundian shorelines of Lake Tanganyika near Bujumbura, where morph BIT was sampled, are very densely populated by humans and heavily disturbed by sedimentation and eutrophication
[65,66] (Figure 2). Most of the cerithioids endemic to Lake Tanganyika, like many other taxa including fishes and ostracodes, are adapted to rocky substrates and increased sedimentation strongly affects their communities [67-69]. Simultaneously, it may open ecological opportunities for invasive taxa that prefer soft substrates. In Lake Malawi the invaders first occurred on the shallow sandy shores of Cape Maclear/Monkey Bay in the south, where increased eutrophication and sedimentation likewise occur $[21,70]$. The small streams and swamps bordering agricultural land near the city of Kisangani that are inhabited by morph CDI are likewise heavily polluted (Additional file 3: Table S3).

Geographical modeling indicated that the localities where invasive Melanoides populations were recorded represent a selective set of highly populated areas rather than a random sample of localities in sub-Saharan Africa with respect to human population (Figure 6). Our observations hence indicate that ecosystem deterioration and anthropogenic stressors increase the susceptibility of ecosystems to colonization by invasive species. However, several factors may contribute to this pattern. Anthropogenic ecosystem deterioration may create ecological opportunities for invaders, but larger human population densities and changes in human behavior also increase the frequency with which alien propagules arrive. Another aspect that potentially contributed to invaders being mainly observed in densely populated areas could be that these areas provide more accessible sampling spots (e.g. because of better infrastructure), and hence, chances to detect invasions may be greater in densely populated areas. Nevertheless, we sampled many localities outside urban areas as well (Table 1), and, hence, we consider it unlikely that the observed patterns would be caused solely by the last factor.

\section{Conservation concerns}

Competitive interactions between invasive and native taxa may develop, certainly if the invader becomes established and migrates into previously unaffected environments. For example, in Lake Malawi negative spatial correlations are observed between the invasive LMI morphs and endemic Melanoides species, which suggests that competition may exist [24]. In the Kisangani area invasive $M$. tuberculata occurs in micro-sympatry with endemic cerithioids (Potadoma), and in Lake Tanganyika in close vicinity to habitats occupied by endemic cerithioids (Tiphobia and Lavigeria), but existing data do not allow assessing whether resource competition between endemic taxa and the invader occurs in these localities. Beyond regional endemism in Potadoma [30,71] endemic Melanoides species occur in the Kisangani area, but micro-sympatry was not observed between native and invasive Melanoides in this region. 
Cerithioid gastropods are ecologically important and often represent a significant component of benthic communities in terms of diversity, biomass and nutrient recycling [69,72]. Lake Tanganyika, the Congo River and Lake Malawi are home to the most diverse freshwater cerithioid communities of the African continent. In Lake Tanganyika $>10$ endemic cerithioid genera occur and the latter two freshwater bodies are hot spots for endemic richness in native Melanoides species (12-13 [excluding taxa endemic to Lake Mweru] and 8 endemic species, respectively, accounting combined for two-thirds of the native Melanoides on the African continent; [30,31]). Recurrent invasions of non-indigenous species may result in competitive interactions between invaders and the native fauna, and beyond the elimination of native biodiversity, hybridization and genetic homogenization are eminent concerns for endemic biodiversity $[2,20,73]$.

Multiple anthropogenically-induced environmental stressors regularly interact with each other, which results in a faster deterioration of ecosystem stability than anticipated from individual stressors alone [11]. The interactions between multiple stressors may directly or indirectly favor invasions and therewith biotic globalization [16]. The occurrence of some ecosystem stressors may hence increase the likelihood that additional stressors arise. In the benthic environments of long-lived lakes increased runoff, sedimentation and eutrophication are powerful agents of change $[9,12,69]$ that may create new ecospace and ecological opportunities for invaders to settle. Intensified surveys with the aim of detecting biological invasions are required and perhaps the monitoring of aquatic invasions should, beyond biodiversity hotspots, also focus on stressed sites, where greater ecological opportunities for opportunistic, eurytopic invaders may be present. Better insights into the interactions between invasive and native taxa are urgently needed in long-lived lakes. Once invaders get established their effects are very difficult or nearly impossible to remove from ecosystems, so our best chance to restrict their impact perhaps lies in integrated ecosystem conservation and attempts to diminish the frequency of biotic introductions.

\section{Conclusions}

Phylogenetic analyses of Melanoides specimens from sub-Saharan Africa with new methods removed previously existing inconsistencies between gene trees and documented the existence of multiple, independent invasions of Asian M. tuberculata to Africa. Our analyses furthermore indicated that $M$. tuberculata is polyphyletic, and the endemic, African Melanoides species as well, which highlights the need for more phylogenetic and systematic work. The areas that were invaded by Asian $M$. tuberculata all have high human population densities and anthropologically stressed aquatic ecosystems indicating that humans strongly determine colonization success. Affected ecosystems include long-lived Lakes Malawi and Tanganyika, and the Congo River, each of which has high endemic diversity in Cerithioidea. Morphological studies document overlaps in shell morphology between native and invasive $M$. tuberculata populations, and some invasive populations display great phenotypic plasticity, which appears to benefit their dispersal capabilities. The cryptic M. tuberculata invasions on a continental scale in Africa highlight the need for more concerted and integrated conservation strategies.

\section{Accession numbers}

All DNA sequences used in this study are available from NCBI GenBank. Accession numbers are provided in Table 1.

\section{Additional files}

Additional file 1: Table S1. Cycling conditions for polymerase chain reactions used to amplify gene fragments.

Additional file 2: Table S2. Results of ancestral range reconstructions with Lagrange at nodes in the ingroup.

Additional file 3: Table S3. Ecological data for localities where newly discovered invasive morphs of Melanoides tuberculata were found.

\section{Competing interests}

The authors declare that they have no competing interests.

\section{Authors' contributions}

BVB and CA conceived and designed the study. BVB, JPME, AK, and OWN performed fieldwork in Africa; BVB and CC performed molecular and morphological analyses; BVB performed geographic modeling. BVB led the writing of the paper. All authors read and approved the final manuscript.

\section{Acknowledgements}

The Congo Biodiversity Consortium supported fieldwork in the Congo Basin and the Official University of Ruwenzori (Vikandy S. Mambo, Meni Malikwicha) in Eastern Congo. Fieldwork support in the DRC was provided by Ernest Tambwe Lukosha. Daniel Engelhard, Thies Geertz and Roland Schultheiß collected samples in Uganda, the DRC and Rwanda. Thomas von Rintelen kindly provided collection data. Torsten Hauffe and Björn Stelbrink provided help with geographical modeling and phylogenetic inference, respectively. Constructive input on an earlier draft was provided by Jon Todd. The manuscript was reviewed independently by Axios Review; the handling editor Melania Cristescu and four anonymous referees provided many constructive suggestions that significantly improved the paper. Funding was received from the Flanders Research Foundation, the Belgian American Educational Foundation, a Peter Buck Fellowship of the Smithsonian Institution and an Alexander von Humboldt Fellowship to B.V.B., a Fellowship of the German Academic Exchange Service to J.-P.M.E., and DFG grants AL 1076/6-2, 7-1, 8-1 to C.A.

\section{Author details}

'Department of Animal Ecology and Systematics, Justus Liebig University Giessen, Heinrich-Buff-Ring 26-32 (IFZ), D-35392 Giessen, Germany.

${ }^{2}$ Departments of Paleobiology and Invertebrate Zoology, National Museum of Natural History, Smithsonian Institution, 10th and Constitution NW, Washington, DC 20560, USA. ${ }^{3}$ Research Unit Palaeontology, Department of Geology and Soil Science, Ghent University, Krijgslaan 281 (S8), 9000 Ghent, Belgium. ${ }^{4}$ Museum für Naturkunde, Leibniz Institute for Evolution and 
Biodiversity Science, Invalidenstraße 43, 10115 Berlin, Germany. ${ }^{5}$ Department of Hydrobiology and Aquaculture, University of Kisangani, BP 2012, Kisangani, D. R. Congo. ${ }^{6}$ Department of Hydrobiology, Official University of Ruwenzori, BP 560, Butembo, D. R. Congo.

\section{Received: 22 January 2015 Accepted: 27 January 2015} Published online: 07 March 2015

\section{References}

1. Strayer DL. Alien species in fresh waters: ecological effects, interactions with other stressors, and prospects for the future. Freshwat Biol. 2010;55 Suppl 1:152-74.

2. Rahel FJ. Homogenization of freshwater faunas. Annu Rev Ecol Syst. 2002;33:291-315

3. Lockwood JL, Hoopes MF, Marchetti MP. Invasion ecology. Malden: Blackwell Publishing Ltd; 2007.

4. Pejchar L, Mooney HA. Invasive species, ecosystem services and human well-being. Trends Ecol Evol. 2009;24(9):497-504.

5. Kolar CS, Lodge DM. Progress in invasion biology: predicting invaders. Trends Ecol Evol. 2001;16(4):199-204.

6. Gherardi F, Gollasch S, Minchin D, Olenin S, Panov VE. Alien invertebrates and fish in European inland waters. In: Drake JA, editor. Handbook of alien species in Europe. Dordrecht: Springer; 2009. p. 81-92.

7. Barel CDN, Dorit R, Greenwood PH, Fryer G, Hughes N, Jackson PBN, et al. Destruction of fisheries in Africa's lakes. Nature. 1985;315:19-20.

8. Witte F, Goldschmidt T, Wanink J, van Oijen M, Goudswaard K, Witte-Maas E, et al. The destruction of an endemic species flock: quantitative data on the decline of the haplochromine cichlids of Lake Victoria. Environ Biol Fishes. 1992;34:1-28.

9. Hecky RE, Mugidde R, Ramlal PS, Talbot MR, Kling GW. Multiple stressors cause rapid ecosystem change in Lake Victoria. Freshwat Biol. 2010;55 Suppl 1:19-42.

10. Pringle RM. The origins of the Nile Perch in Lake Victoria. Bioscience. 2005:55:780-7.

11. Donohue I, Petchey OL, Montoya JM, McNally L, Viana M, Healy K, et al. On the dimensionality of ecological stability. Ecol Lett. 2013;16:421-9.

12. Van Bocxlaer B, Albrecht C, Stauffer JR. Growing population and ecosystem change increase human schistosomiasis around Lake Malawii. Trends Parasitol. 2014;30(5):217-20.

13. Herben T. Species pool size and invasibility of island communities: a null model of sampling effects. Ecol Lett. 2005;8(9):909-17.

14. Davis MA. Biotic globalization: does competition from introduced species threaten biodiversity? Bioscience. 2003;53:481-9.

15. Lambrinos JG. How interactions between ecology and evolution influence contemporary invasion dynamics. Ecology. 2004;85(8):2061-70.

16. Shea K, Chesson P. Community ecology theory as a framework for biological invasions. Trends Ecol Evol. 2002;17(4):170-6.

17. Facon B, Pointier J-P, Jarne P, Sarda V, David P. High genetic variance in life-history strategies within invasive populations by way of multiple introductions. Curr Biol. 2008;18:363-7.

18. Samadi S, Mavárez J, Pointier J-P, Delay B, Jarne P. Microsatellite and morphological analysis of population structure in the parthenogenetic freshwater snail Melanoides tuberculata: insights into the creation of clonal variability. Mol Ecol. 1999:8:1141-53.

19. Pointier J-P. Conchological studies of Thiara (Melanoides) tuberculata (Mollusca: Gastropoda: Thiaridae) in the French West Indies. Walkerana. 1989;3:203-9.

20. Facon B, Pointier J-P, Glaubrecht M, Poux C, Jarne P, David P. A molecular phylogeography approach to biological invasions of the New World by parthenogenetic thiarid snails. Mol Ecol. 2003;12:3027-39.

21. Genner MJ, Michel E, Erpenbeck D, De Voogd N, Witte F, Pointier J-P. Camouflaged invasion of Lake Malawi by an Oriental gastropod. Mol Ecol. 2004;13:2135-41

22. Sørensen LVG, Jørgensen A, Kristensen TK. Molecular diversity and phylogenetic relationships of the gastropod genus Melanoides in Lake Malawi. Afr Zool. 2005;40(2):179-91.

23. Genner MJ, Michel E, Todd JA. Resistance of an invasive gastropod to an indigenous trematode parasite in Lake Malawi. Biol Invasions. 2008;10:41-9.

24. Van Bocxlaer B, Albrecht C. Ecosystem change and establishment of an invasive snail alter gastropod communities in long-lived Lake Malawi. Hydrobiologia. 2015;744:307-16.
25. Pfenninger M, Weigand A, Bálint M, Klussmann-Kolb A. Misperceived invasion: the Lusitanian slug (Arion lusitanicus auct. non-Mabille or Arion vulgaris Moquin-Tandon 1855) is native to Central Europe. Evol Appl. 2014:7:702-13.

26. Knop E, Reusser N. Jack-of-all-trades: phenotypic plasticity facilitates the invasion of an alien slug species. Proc R Soc B Biol Sci. 2012;279:4668-76.

27. Gurdebeke PR, Van Bocxlaer B. Conchological differentiation in an ongoing radiation of Lanistes gastropods from ancient Lake Malawi: how adaptive is shell morphology? Geologica Belgica. 2013;16(1-2):118-9.

28. Hauffe T, Schultheiß R, Van Bocxlaer B, Prömmel K, Albrecht C. Environmental heterogeneity predicts species richness of freshwater mollusks in sub-Saharan Africa. Int J Earth Sci. 2014 (online early; doi 10.1007/s00531-014-1109-3)

29. Amante C, Eakins BW. ETOPO1 1 Arc-minute global relief model: procedures, data sources and analysis. NOAA Technical Memorandum NESDIS NGDC-24. Boulder, CO National Geophysical Data Center, NOAA; 2009. Doi: 10.7289/ V5C8276M. Accessed November 2014

30. Danish Bilharziasis Laboratory. Guide de terrain des gastéropodes d'eau douce africains 5: Afrique centrale. Charlottenlund, Denmark: Danish Bilharziasis Laboratory; 1982.

31. Brown DS. Freshwater snails of Africa and their medical importance. 2nd ed. London: Taylor and Francis; 1994.

32. Van Bocxlaer B, Schultheiß R. Comparison of morphometric techniques for shapes with few homologous landmarks based on machine-learning approaches to biological discrimination. Paleobiology. 2010;36(3):497-515.

33. Venables WN, Ripley BD. Modern applied statistics with S. 4th ed. New York: Springer; 2002.

34. Oksanen J, Blanchet FG, Kindt R, Legendre P, Minchin PR, O'Hara RB, et al. Vegan: Community Ecology Package. R package; version 2.0-10; 2013.

35. R Development Core Team. R: A language and environment for statistical computing. Version 3.0.1. R Foundation for Statistical Computing; 2013.

36. Wilke T, Davis GM, Qui DC, Spear RC. Extreme mitochondrial sequence diversity in the intermediate schistosomiasis host Oncomelania hupensis: another case of ancestral polymorphism? Malacologia. 2006;48:143-57.

37. Folmer O, Black M, Hoeh W, Lutz R, Vrijenhoek R. DNA primers for amplification of mitochondrial cytochrome c oxidase subunit I from diverse metazoan invertebrates. Mol Mar Biol Biotechnol. 1994;3(5):294-9.

38. Schultheiß R, Wilke T, Jørgensen A, Albrecht C. The birth of an endemic species flock: demographic history of the Bellamya group (Gastropoda, Viviparidae) in Lake Malawi. Biol J Linn Soc. 2011;102:130-43.

39. Palumbi S, Martin A, Romano S, Mcmillian WO, Stice L, Grabowski G. The simple fool's guide to PCR. Honolulu: University of Hawaii; 1991.

40. Hall TA. BioEdit: a user-friendly biological sequence alignment editor and analysis program for Windowns 95/98/NT. Nucleic Acids Symp Ser. 1999;41:95-8

41. Löytynoja A, Goldman N. An algorithm for progressive multiple alignment of sequences with insertions. Proc Natl Acad Sci U S A. 2005;102:10557-62.

42. Xia X, Lemey P. Assessing substitution saturation with DAMBE. In: Lemey P, Salemi M, Vandamme A-M, editors. The phylogenetic handbook: a practica approach to DNA and protein phylogeny. 2nd ed. Cambridge: Cambridge University Press; 2009. p. 615-630.

43. Posada D. jModelTest: phylogenetic model averaging. Mol Biol Evol. 2008;25(7):1253-6.

44. Drummond AJ, Rambaut A. BEAST: Bayesian evolutionary analysis by sampling trees. BMC Evol Biol. 2007;7:214.

45. Kass RE, Raftery AE. Bayes factors. J Am Stat Assoc. 1995;90:773-95.

46. Suchard MA, Weiss RE, Sinsheimer JS. Bayesian selection of continuous-time Markov chain evolutionary models. Mol Biol Evol. 2001;18:1001-13.

47. Paradis E, Bolker B, Claude J, Cuong HS, Desper R, Durand B, et al. APE: analyses of phylogenetics and evolution. R package; version 3.1-4; 2014.

48. Harmon L, Weir J, Brock C, Glor R, Challenger W, Hunt G, et al. Geiger: analysis of evolutionary diversification. R package; version 2.0.3; 2014.

49. Ree RH, Smith SA. Maximum likelihood inference of geographic range evolution by dispersal, local extinction, and cladogenesis. Syst Biol. 2008:57:4-14.

50. Center for International Earth Science Information Network (CIESIN), Columbia University, United Nations Food and Agriculture Programme (FAO), Centro Internacional de Agricultura Tropical (CIAT). Gridded population of the World, Version 3 (GWP): Population Count Grid, Future Estimates. Palisades, NY: NASA Socioeconomic Data and Applications 
Center (SEDAC); 2005. http://sedac.ciesin.columbia.edu. Accessed 15 October 2014

51. Hijmans RJ. Raster: Geographic data analysis and modeling. R package version 2.2-31; 2014.

52. Bivand R, Keitt T, Rowlingson B. rgdal: bindings for the Geospatial Data Abstraction Library. R package; version 0.9-1; 2014.

53. Hijmans RJ, Phillips S, Leathwick J, Elith J. dismo: species distribution modeling. R package; version 0.9-3; 2013.

54. Genner MJ, Todd JA, Michel E, Erpenbeck D, Jimoh A, Joyce DA, et al. Amassing diversity in an ancient lake: evolution of a morphologically diverse parthenogenetic gastropod assemblage in Lake Malawi. Mol Ecol. 2007;16(3):517-30.

55. Mandahl-Barth G. The freshwater Mollusca of Lake Malawi. Revue de Zoologie et de Botanique Africaines. 1972;86:257-89.

56. Van Bocxlaer B, Salenbien W, Praet N, Verniers J. Stratigraphy and paleoenvironments of the early to middle Holocene Chipalamawamba Beds (Malawi Basin, Africa). Biogeosciences. 2012;9:4497-512.

57. Schultheiß R, Van Bocxlaer B, Riedel F, von Rintelen T, Albrecht C. Disjunct distributions of freshwater snails testify to a central role of the Congo system in shaping biogeographic patterns in Africa. BMC Evol Biol. 2014;14:42.

58. Glaubrecht M, Strong EE. Ancestry to an endemic radiation in Lake Tanganyika? Evolution of the viviparous gastropod Potadomoides Leloup, 1953 in the Congo River System (Caenogastropoda, Cerithioidea, Paludomidae). Biol J Linn Soc. 2007;92(2):367-401.

59. Kullander SO, Roberts TR. Out of Lake Tanganyika: endemic lake fishes inhabit rapids of the Lukuga River. Ichtyol Explor Freshwaters. 2011;22 (4):355-76.

60. Salzburger W, Mack T, Verheyen E, Meyer A. Out of Tanganyika: genesis, explosive speciation, key-innovations and phylogeography of the haplochromine cichlid fishes. BMC Evol Biol. 2005;5:17.

61. Seegers $L$. The fishes of the Lake Rukwa drainage. Annales du Musée Royal de l'Afrique Centrale, Sciences Zoologiques. 1996;278:1-407.

62. Cohen AS, Van Bocxlaer B, Todd JA, McGlue M, Michel E, Nkotagu HN, et al. Quaternary ostracodes and molluscs from the Rukwa Basin (Tanzania) and their evolutionary and paleobiogeographic implications. Palaeogeogr, Palaeoclimatol, Palaeoecol. 2013;392:79-97.

63. Wilson $A B$, Glaubrecht $M$, Meyer $A$. Ancient lakes as evolutionary reservoirs: evidence from the thalassoid gastropods of Lake Tanganyika. Proc R Soc B Biol Sci. 2004;271:529-36.

64. Ndifon GT, Ukoli FMA. Ecology of freshwater snails in south-western Nigeria. I. Distribution and habitat preferences. Hydrobiologia. 1989;171 (3):231-53.

65. Alin SR, Cohen AS, Bills R, Gashagaza MM, Michel E, Tiercelin JJ, et al. Effects of landscape disturbance on animal communities in Lake Tanganyika, East Africa. Conserv Biol. 1999;13:1017-33.

66. Eggermont $\mathrm{H}$, Verschuren D. Impact of soil erosion in disturbed tributary drainages on the benthic invertebrate fauna of Lake Tanganyika, East Africa. Biol Conserv. 2003;113:99-109.

67. Cohen AS, Bills R, Cocquyt CZ, Caljon AG. The impact of sediment pollution on biodiversity in Lake Tanganyika. Conserv Biol. 1993;7:667-77.

68. Donohue I, Verheyen E, Irvine K. In situ experiments on the effects of increased sediment loads on littoral rocky shore communities in Lake Tanganyika, East Africa. Freshwat Biol. 2003;48:1603-16.

69. Mclntyre PB, Michel E, France K, Rivers A, Hakizimana P, Cohen AS Individual- and assemblage-level effects of anthropogenic sedimentation on snails in Lake Tanganyika. Conserv Biol. 2005;19(1):171-81.

70. Otu MK, Ramlal P, Wilkinson P, Hall Rl, Hecky RE. Paleolimnological evidence of the effects of recent cultural eutrophication during the last 200 years in Lake Malawi, East Africa. J Great Lakes Res. 2011;37:61-74.
71. Pilsbry HA, Bequaert J. The aquatic molluscs of the Belgian Congo, with a geographical and ecological account of Congo malacology. Bull Am Mus Nat Hist N Y. 1927;53:69-602.

72. Strong EE, Colgan DJ, Healy JM, Lydeard C, Ponder WF, Glaubrecht M. Phylogeny of the gastropod superfamily Cerithioidea using morphology and molecules. Zool J Linn Soc. 2011;162:43-89.

73. Mooney HA, Cleland EE. The evolutionary impact of invasive species. Proc Natl Acad Sci U S A. 2001;98(10):5446-51.

\section{Submit your next manuscript to BioMed Central and take full advantage of:}

- Convenient online submission

- Thorough peer review

- No space constraints or color figure charges

- Immediate publication on acceptance

- Inclusion in PubMed, CAS, Scopus and Google Scholar

- Research which is freely available for redistribution 